\title{
Analysis of key clinical features for achieving complete remission in stage III and IV non-small cell lung cancer patients
}

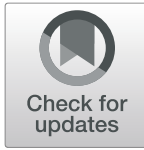

Takuya Aoki ${ }^{1 *}$ D, Takeshi Akiba², Jun Nishiyama ${ }^{3}$, Sakurako Tajiri', Naoki Hayama', Genki Takahashi', Jun Tanaka', Masako Sato ${ }^{1}$, Hiroto Takiguchi ${ }^{1}$, Hiromi Tomomatsu' ${ }^{1}$, Katsuyoshi Tomomatsu', Takahisa Takihara ${ }^{1}$, Kyoko Niimi ${ }^{1}$, Tsuyoshi Oguma' ${ }^{1}$ Mitsutomo Kohno ${ }^{4}$, Ryota Masuda ${ }^{4}$, Tetsuya Urano ${ }^{1}$, Hitoshi Itoh ${ }^{5}$, Hiroshi Kajiwara ${ }^{5}$, Naoya Nakamura ${ }^{5}$, Etsuo Kunieda ${ }^{2}$, Mitsunori Matsumae ${ }^{3}$, Masayuki Iwazaki ${ }^{4}$ and Koichiro Asano ${ }^{1}$

\begin{abstract}
Background: Although development of immune checkpoint inhibitors and various molecular target agents has extended overall survival time (OS) in advanced non-small cell lung cancer (NSCLC), a complete cure remains rare. We aimed to identify features and treatment modalities of complete remission (CR) cases in stages III and IV NSCLC by analyzing long-term survivors whose OS exceeded 3 years.

Methods: From our hospital database, 1,699 patients, registered as lung cancer between $1^{\text {st }}$ Mar 2004 and $30^{\text {th }} \mathrm{Apr}$ 2011, were retrospectively examined. Stage III or IV histologically or cytologically confirmed NSCLC patients with chemotherapy initiated during this period were enrolled. A Cox proportion hazards regression model was used. Data collection was closed on $13^{\text {th }}$ Feb 2017.

Results: There were 164 stage III and 279 stage IV patients, including 37 (22.6\%) and 51 (18.3\%) long-term survivors and $12(7.3 \%)$ and $5(1.8 \%)$ CR patients, respectively. The long-term survivors were divided into three groups: $3 \leq$ OS $<5$ years, 5 years $\leq$ OS with tumor, and 5 years $\leq$ OS without tumor (CR). The median OS of these groups were $1,405,2,238$, and 2,876 days in stage III and 1,368,2,503, and 2,643 days in stage IV, respectively. The mean chemotherapy cycle numbers were 16,20 , and 10 in stage III and 24, 25, and 5 in stage IV, respectively. In the stage III CR group, all patients received chemoradiation, all oligometastases were controlled by radiation, and none had brain metastases. Compared with non-CR patients, the stage IV CR patients had smaller primary tumors and fewer metastases, which were independent prognostic factors for OS among long-term survivors. The $80 \%$ stage IV CR patients received radiation or surgery for controlling primary tumors, and the surgery rate for oligometastases was high. Pathological findings in the stage IV CR patients revealed that numerous inflammatory cells existed around and inside resected lung and brain tumors, indicating strong immune response.
\end{abstract}

Conclusions: Multiple line chemotherapies with primary and oligometastatic controls by surgery and/or radiation might achieve cure in certain advanced NSCLC. Cure strategies must be changed according to stage III or IV. This study was retrospectively registered on $16^{\text {th }}$ Jun 2019 in UMIN Clinical Trials Registry (number UMIN000037078).

Keywords: advanced non-small cell lung cancer, oligometastases, complete remission, radiation, surgery

\footnotetext{
* Correspondence: ZWQ00221@nifty.ne.jp

${ }^{1}$ Respiratory Division, Department of Internal Medicine, Tokai University

School of Medicine, Isehara, Kanagawa 259-1193, Japan

Full list of author information is available at the end of the article
}

(c) The Author(s). 2019 Open Access This article is distributed under the terms of the Creative Commons Attribution 4.0 International License (http://creativecommons.org/licenses/by/4.0/), which permits unrestricted use, distribution, and reproduction in any medium, provided you give appropriate credit to the original author(s) and the source, provide a link to the Creative Commons license, and indicate if changes were made. The Creative Commons Public Domain Dedication waiver (http://creativecommons.org/publicdomain/zero/1.0/) applies to the data made available in this article, unless otherwise stated. 


\section{Introduction}

The ultimate treatment goal for advanced non-small cell lung cancer (NSCLC) is complete cure. Through the era of chemotherapy as the main treatment option against advanced NSCLC [1-3] for approximately 30 years and even today, various therapeutic strategies have been developed based on a wide range of clinical trials and basic research studies. Consequently, two important new treatments were created: molecular target therapies against driver mutations of oncogenes $[4,5]$ and immune checkpoint inhibitors (ICI) [6]. The former includes epidermal growth factor receptor-tyrosine kinase inhibitors (EGFRTKI) [7-9], anaplastic lymphoma kinase-tyrosine kinase inhibitors (ALK-TKI) [10-12], c-ros oncogene 1 (ROS-1) inhibitors [13], v-raf murine sarcoma viral oncogene homolog B1 (BRAF) inhibitors [14], or rearranged during transfection (RET) inhibitors $[15,16]$. The latter includes nivolumab $[17,18]$, pembrolizumab $[19,20]$, atezolizumab [21] and durvalumab [22]. Discoveries of programmed cell death 1 (PD-1) [23] and cytotoxic T-lymphocyte antigen 4 (CTLA-4) [24] were major breakthroughs, and the disclosure of their roles [25-28] in tumor immune environments has led to the creation of ICI $[6$, $29,30]$, which caused a paradigm shift in cancer treatments. The creation of ICI proved that human immune mechanisms have marked capacity to attack cancers. Owing to this evidence, new innovative treatments are actively being developed. In the near future, combining ICI with other chemotherapies [31, 32] may lead to complete cure in some advanced NSCLC patients, although the development of biomarkers might be crucial to achieving this goal.

On the other hand, controlling oligometastatic disease has been theoretically proposed for curing advanced NSCLC [33], and treatment approaches include stereotactic radiotherapy (SRT), conventionally fractionated radiotherapy, surgery, and radiofrequency ablation (RFA) [34-38]. Clinical trials for oligometastatic diseases have been actively conducted in radiotherapy $[39,40]$, surgery [41], or both radiotherapy and surgery [42-44], however, optimal treatment approaches, i.e. radiation versus surgery, for the control of oligometastases have not been determined. Moreover, patient selection and the number of metastases, which is regarded as being treatable, have not been established [45]. The superiority of stereotactic ablative radiotherapy as compared to the standard of care palliative treatment was recently demonstrated by a prospective randomized clinical trial [46]. According to this report, three metastases in one organ and a total of 5 metastases were treated. This number might serve as one of the indexes for treatable oligometastases. Although many treatment options and modalities have been developed, the key features of cured patients with advanced NSCLC have not yet been elucidated.
Molecular target therapies produce long-term survival, and ICI also prolong survival, a phenomenon known as the tail effect. Complete cure in advanced NSCLC patients empirically occurs very rarely among long-term survivors.

We hypothesized that information on the clinical differences in patient characteristics, lung tumor features and treatment options, including modalities for oligometastatic control, between long-term survivors with and without complete remission (CR), might provide very important clues to achieve complete cure in the treatment of advanced NSCLC. This study was designed to identify the features of advanced NSCLC patients with $\mathrm{CR}$ by comparing these factors among long-term survivors whose overall survival time (OS) exceeded 3 years. Complete remission, for the purposes of this study, was defined as sustained CR over the five-year follow-up period since initial treatment, without previous one-year treatment.

\section{Methods \\ Patients}

This retrospective study was approved by the institutional review board for clinical research, Tokai University (14R054). The study was performed in accordance with the Declaration of Helsinki. All patients registered as having lung cancer in our hospital database between $1^{\text {st }}$ Mar 2004 and $30^{\text {th }}$ Apr 2011 were retrospectively examined. The study eligibility criteria for patients were as follows: stage III or IV (The International Association for the Study of Lung Cancer: IASLC $8^{\text {th }}$ edition of the TNM classification for lung cancer) [47], histologically or cytologically confirmed NSCLC, and chemotherapy or EGFRTKI administration had been initiated between $1^{\text {st }}$ Mar 2004 and $30^{\text {th }}$ Apr 2011. The dataset was closed on $13^{\text {th }}$ Feb 2017, and the final analyses were performed on $10^{\text {th }}$ Aug 2018.

The primary outcome of interest was the OS of all eligible NSCLC patients. The secondary endpoints were patient characteristics, tumor characteristics, and treatment contents and modalities in long-term survivors, whose OS exceeded 3 years, and CR patients. The longterm survivors were divided into three groups: $3 \leq$ OS $<$ 5 years $(3 \leq$ OS $<5), 5$ years $\leq$ OS with tumor $(5 \leq$ OS tumor + ), and 5 years $\leq$ OS without tumor and no previous one-year treatment ( $5 \leq \mathrm{OS}$ tumor -: CR). The features of $\mathrm{CR}$ patients were compared among these three groups. OS was defined as elapsed time between the starting date of first chemotherapy or EGFR-TKI administration and the date of death.

\section{Study design and treatment}

This study was a single institutional retrospective study conducted for 13 years. The patients were treated at Tokai 
University Hospital in Kanagawa, Japan. The treatments were multiple line treatments, and chemotherapies were fully continued according to the American Society of Clinical Oncology (ASCO) guidelines, the National Comprehensive Cancer Network (NCCN) guidelines or the Japan Lung Cancer Society guidelines. Oligometastases, which include oligoreccurences, were considered to control with radiation and/or surgery if patients under various conditions were allowed to receive these modalities and patients hope to receive these treatments.

The extracted data included age, sex, histology, and OS for all enrolled patients, and age, sex, smoking status, body mass index (BMI), Eastern Cooperative Oncology Group (ECOG) performance status (PS), histology, EGFR mutation status, primary tumor diameter, $\mathrm{N}$ factor, $\mathrm{M}$ factor, total metastatic number, treatment line number, total cycle number, EGFR-TKI usage, EGFR-TKI line number, radiation treatment (primary site and metastatic lesions), surgery (primary and metastatic lesions), treatment of brain metastases (SRT, surgery, and/or whole brain irradiation (WBI)) for long-term survivors. All treatments were examined until death. Total metastatic lesion numbers exceeding 10 and carcinomatous lymphangitis at the time of diagnosis were counted as 10 lesions.

\section{Statistical analysis}

The significance of intergroup differences was determined by the Kruskal-Wallis test, and the Dunn test was used to identify significant differences. The chi-squared test was applied to compare categorical variables. OS was estimated using the Kaplan-Meier method, and median time was reported with $95 \%$ confidence intervals (CI). A Cox proportion hazards regression model was used to test the association of each factor with survival time, and a stepwise selection procedure was implemented to identify the independent prognostic roles of patient characteristics. Hazard ratios (HRs) and their 95\% CIs were calculated. Differences were considered statistically significant at $\mathrm{P}<0.05$. All statistical analyses were performed using Stat Flex ver. 6.0 statistical software (Artech Co., Ltd., Osaka, Japan).

\section{Results}

\section{Enrolled patients}

From our hospital database, 1,699 patients were registered as having lung cancer between $1^{\text {st }}$ Mar 2004 and $30^{\text {th }}$ Apr 2011. Among these 1699 patients, 164 stage III and 279 stage IV patients who met the eligibility criteria for this clinical study were enrolled. There were also 144 patients with small cell carcinoma, 287 with early stages who underwent surgery, 113 with only radiation treatment, 109 with best supportive care without chemotherapy, 15 with stage I or II with chemotherapy or chemoradiation, and 588 patients in whom lung cancer could not be confirmed.

The baseline characteristics of the enrolled patients are shown in Table 1 . The median age of stage III patients was 68 years (range 41-88), and these patients were older than the stage IV patients (65 years; range 32-89). The proportion of males in the stage III group was larger than that in the stage IV group. Regarding histological types, the proportion of squamous cell carcinoma was highest among stage III patients, while that of adenocarcinoma was highest among stage IV patients.

OS data are shown in Fig. 1. The median OS for stage III patients was 507 days (95\% CI; 407-673 days) and 342 days (95\% CI; 306-412 days) for stage IV patients. Tail effects were observed in both stage III and stage IV patients.

\section{Long-term survivors}

There were 37 (22.6\%) stage III and 51 (18.3\%) stage IV long-term survivors. The baseline characteristics of the long-term survivors are shown in Table 2. Although there were significant differences between the stage III and stage IV patients in age, age distribution and sex (Table 1), there were no significant differences in these factors among the long-term survivors (Table 2). There were also no significant differences in smoking status, BMI, EGFR mutation status, ECOG PS, primary tumor diameters and $\mathrm{N}$ factor between the stage III and IV long-term survivors. Regarding the histological types of the tumors in long-term survivors, the adenocarcinoma proportion was the highest among both stage III and IV patients.

There were 13 (7.9\%), 12 (7.3\%), and 12 (7.3\%) patients in the $3 \leq$ OS $<5$, the $5 \leq$ OS tumor + , and the CR groups of stage III patients, respectively, and the corresponding median OS for these groups were 1,405 days, 2,238 days, and 2,876 days (Table 3). There were no differences in age, sex, smoking status, BMI, tumor histology, ECOG PS, primary tumor diameter, and $\mathrm{N}$ factor. EGFR mutation status was different among the three groups of stage III long-term survivors (Table 3). We also analyzed the influences of occupations/jobs and complications. There were no differences in these parameters among long-term survivors of stage III NSCLC (Table 3).

Among the stage IV long-term survivors, there were $29(10.4 \%), 17(6.1 \%)$, and $5(1.8 \%)$ patients in the 3 $\leq$ OS $<5$, the $5 \leq$ OS tumor + , and the CR groups, respectively, and the median OS for these groups were 1,368 days, 2,503 days, and 2,643 days, respectively (Table 3 ). There were no differences in age, sex, smoking status, BMI, tumor histology, EGFR mutation status, or ECOG PS. The influences of occupations/ 
Table 1. Baseline characteristics of all patients with stage III and stage IV non-small cell lung cancers

\begin{tabular}{lcll}
\hline Variables & $\begin{array}{l}\text { Stage III } \\
(n=164)\end{array}$ & $\begin{array}{l}\text { Stage IV } \\
(n=279)\end{array}$ & P value \\
\hline $\begin{array}{l}\text { Age } \\
\text { Median (Range) - years }\end{array}$ & $68.0(41-88)$ & $65.0(32-89)$ & $<0.01$ \\
$\begin{array}{l}\text { Age distribution } \\
<75-\text { no. (\%) }\end{array}$ & $122(74.4)$ & $232(83.2)$ & $<0.05$ \\
$\geq 75-$ no. (\%) & $42(25.6)$ & $47(16.8)$ & \\
$\begin{array}{l}\text { Sex - no. (\%) } \\
\text { Male }\end{array}$ & $137(83.5)$ & $205(73.5)$ & $<0.05$ \\
Female & $27(16.5)$ & $74(26.5)$ & \\
Histological characteristics of tumor - no. (\%) & & \\
Adenocarcinoma & $61(37.2)$ & $200(71.7)$ & $<0.01$ \\
Large cell carcinoma & $3(1.8)$ & $4(1.4)$ & \\
Squamous cell carcinoma & $69(42.1)$ & $34(12.2)$ & \\
Not otherwise specified & $26(15.9)$ & $32(11.5)$ & \\
Other cell types & $5(3.0)$ & $9(3.2)$ & \\
\hline
\end{tabular}

All significant $P$ values are expressed in boldface, and not significant $P$ values are expressed in plainface jobs and complications were analyzed, and there were no differences in these parameters among long-term survivors of stage IV NSCLC (Table 3).

There were no differences in lymphocyte counts before treatment among the three groups in stage III long-term survivors, while those of the CR group were higher than those of the $3 \leq \mathrm{OS}<5$ group in the stage IV long-term survivors (Table 3 ). The primary tumor diameters in the CR group were smaller than those in the $3 \leq$ OS $<5$ group of stage IV patients (Table 3). The $\mathrm{N}$ factors in stage IV long-term survivors were different among the three groups, and there were no N3 patients in the CR group with stage IV disease. $M$ factors were not different among the groups of the stage IV long-term survivors, while the total metastatic numbers in the CR group were less than those in the $3 \leq \mathrm{OS}<5$ group of stage IV patients (Table 3).

The univariate and multivariate analyses of the HRs in stage III and stage IV long-term survivors are shown in Table 4. Smoking was associated with decreased HRs in both stage III and stage IV long-term survivors by univariate analysis, while the significance of the HRs for smoking disappeared by multivariate analysis. A univariate analysis of the stage IV longterm survivors revealed increases in the diameter of the primary tumor, and $\mathrm{N}$ factor, and metastatic

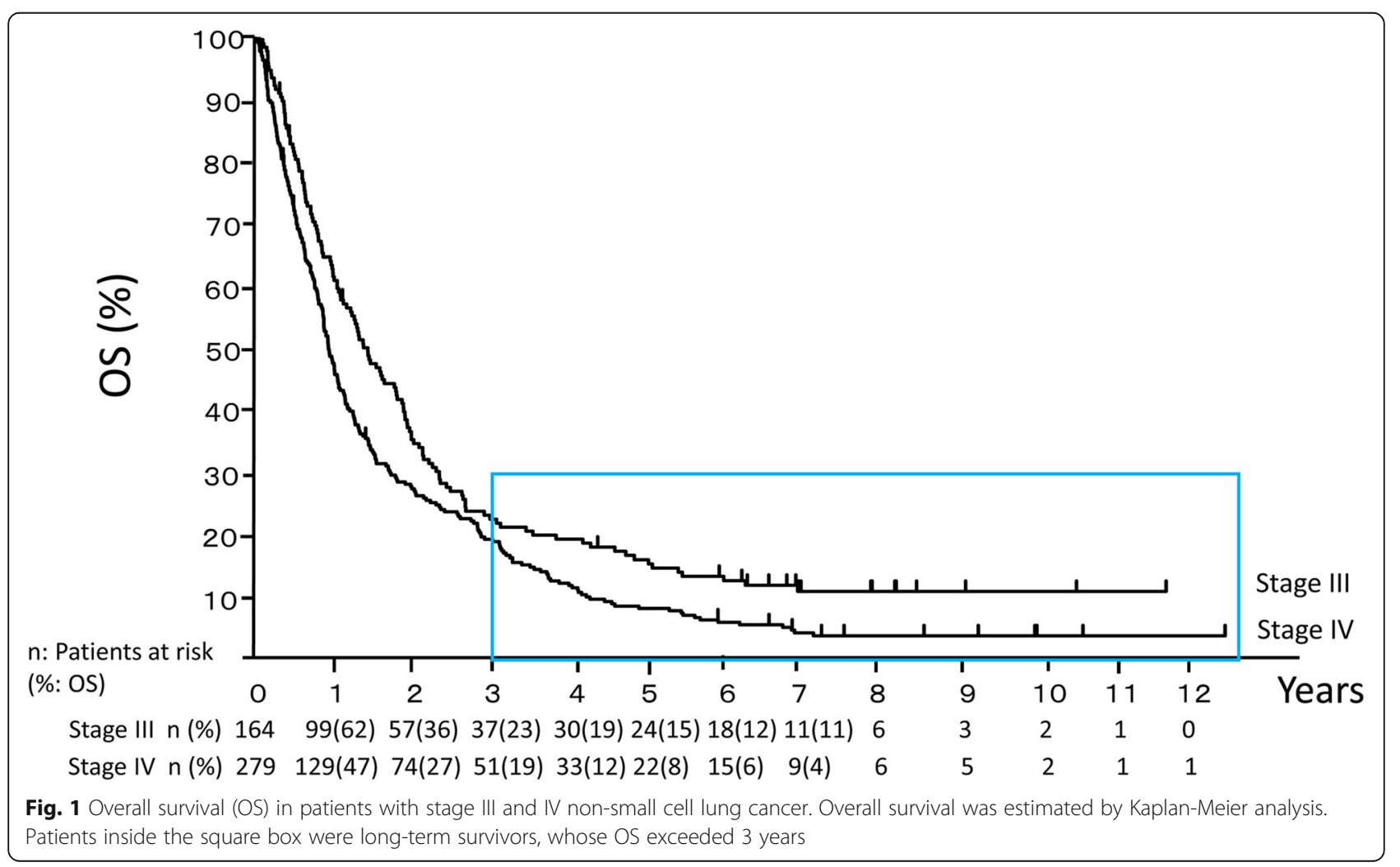


Table 2 Characteristics of the long-term survivors with stage III and stage IV non-small cell lung cancers

\begin{tabular}{|c|c|c|c|}
\hline Variables & $\begin{array}{l}\text { Stage III } \\
(n=37)\end{array}$ & $\begin{array}{l}\text { Stage IV } \\
(n=51)\end{array}$ & $P$ value \\
\hline \multicolumn{4}{|l|}{ Age } \\
\hline Median (Range) - years & $66.0(41-79)$ & $64.0(36-89)$ & 0.56 \\
\hline \multicolumn{4}{|l|}{ Age distribution } \\
\hline$<75-$ no. (\%) & $30(81.1)$ & $43(84.3)$ & \multirow[t]{2}{*}{0.69} \\
\hline$\geq 75-$ no. $(\%)$ & $7(18.9)$ & $8(15.7)$ & \\
\hline \multicolumn{4}{|l|}{ Sex - no. (\%) } \\
\hline Male & $29(78.4)$ & $30(58.8)$ & \multirow[t]{2}{*}{0.06} \\
\hline Female & $8(21.6)$ & $21(41.2)$ & \\
\hline \multicolumn{4}{|l|}{ Smoking status } \\
\hline Current & $16(43.2)$ & $19(37.3)$ & \multirow[t]{3}{*}{0.25} \\
\hline Former & $13(35.1)$ & $13(25.5)$ & \\
\hline Never & $8(21.6)$ & $19(37.3)$ & \\
\hline BMI & $22.2 \pm 3.2$ & $22.2 \pm 3.4$ & 0.74 \\
\hline \multicolumn{4}{|l|}{$\begin{array}{l}\text { Histological characteristics } \\
\text { of tumor - no. }(\%)\end{array}$} \\
\hline Adenocarcinoma & $20(54.1)$ & $41(80.4)$ & \multirow[t]{5}{*}{$<0.05$} \\
\hline Large cell carcinoma & 0 & $1(2)$ & \\
\hline Squamous cell carcinoma & $9(24.3)$ & $3(5.9)$ & \\
\hline Not otherwise specified & $6(16.2)$ & $2(3.92)$ & \\
\hline Other cell types & $2(5.41)$ & $4(7.84)$ & \\
\hline $\begin{array}{c}\text { EGFR mutation status } \\
\text { Positive/Negative/Unknown }\end{array}$ & $4 / 9 / 24$ & $13 / 13 / 25$ & 0.19 \\
\hline \multicolumn{4}{|c|}{ ECOG performance status - no. (\%) } \\
\hline 1 & $17(46.0)$ & $22(43.1)$ & \multirow[t]{2}{*}{0.79} \\
\hline 0 & $20(54.1)$ & 29 (56.9) & \\
\hline $\begin{array}{l}\text { Primary tumor diameter } \\
(\mathrm{mm} ; \text { mean } \pm \mathrm{SD})\end{array}$ & $36.3 \pm 19.3$ & $34.1 \pm 15.3$ & 0.91 \\
\hline \multicolumn{4}{|l|}{ N factor - no. (\%) } \\
\hline N3 & $10(8.11)$ & $15(29.4)$ & \multirow[t]{4}{*}{0.26} \\
\hline N2 & $22(59.5)$ & 19 (37.3) & \\
\hline $\mathrm{N} 1$ & $2(5.41)$ & $4(7.8)$ & \\
\hline NO & $3(8.11)$ & $13(25.5)$ & \\
\hline \multicolumn{4}{|l|}{ M factor - no. (\%) } \\
\hline M1c & 0 & $9(17.6)$ & \\
\hline M1b & 0 & $14(27.5)$ & \\
\hline M1a & 0 & $28(54.9)$ & \\
\hline $\begin{array}{l}\text { Total metastatic number } \\
\text { at initial diagnosis }\end{array}$ & 0 & $5.51 \pm 4.13$ & \\
\hline
\end{tabular}

BMI body mass index, EGFR epidermal growth factor receptor, ECOG Eastern Cooperative Oncology Group.

All significant $P$ values are expressed in boldface, and not significant $P$ values are expressed in plainface

numbers were found to be risk factors for OS. A multivariate analysis of the stage IV long-term survivors revealed increases in BMI, and primary tumor diameter, and total metastatic numbers were independent prognostic factors for OS (Table 4).

\section{Treatment}

The treatment differences among the groups of stage III and IV long-term survivors are shown in Table 5. The treatment line number in the CR group of stage III patients was less than that in the $3 \leq \mathrm{OS}<5$ group, indicating that CR patients did not need many lines of chemotherapy to achieve CR. There was no difference in EGFR-TKI usage among the groups of stage III longterm survivors. Radiation treatment for the primary site was performed in $85 \%, 67 \%$, and $100 \%$ of cases in the 3 $\leq$ OS $<5$, the $5 \leq$ OS tumor + , and the CR groups, respectively, of stage III long-term survivors. All stage III $\mathrm{CR}$ patients received chemoradiation treatment. Three stage III CR patients (25\%) received radiation treatment for metastatic lesions other than brain metastases. No stage III CR patients received surgery for primary or metastatic lesions. No patients received treatments for brain metastases in the stage III CR group because no brain metastases developed in this group.

The treatment line number in the CR group of stage IV long-term survivors was also less than that in the $3 \leq$ $\mathrm{OS}<5$ group. There was no difference in the proportion of EGFR-TKI usage. In the stage IV CR group, 2 patients received radiation therapy for the primary tumor, and 2 patients received radiation therapy for metastatic lesions other than brain metastases, while no patients received radiation treatments for both sites. Two patients received surgery for the primary site, 2 patients received surgery for metastatic lesions other than brain metastases, and 1 patient received surgery for both primary and metastatic lesions. Four out of the $5 \mathrm{CR}$ patients received radiation ( 2 patients) or surgery ( 2 patients) for the primary tumor. The rates of surgery for metastatic lesions other than brain metastases and for both primary and metastatic lesions were different among the groups (Table 5), showing that the rate of surgery for controlling oligometastases was high in the stage IV CR group. One patient in the stage IV CR group received both SRT and brain surgery for brain metastases. No patients in the stage IV CR group were treated with WBI.

A representative CR patient with oligometastatic control in stage III is shown in Fig. 2. The patient was treated with chemoradiation, and oligometastatic states were successfully controlled by positron emission tomography / computed tomography (PET/CT)-assisted 3 dimensional conformal radiation therapy. A male in his 50s, who was referred to our hospital due to an abnormal shadow noted on a chest X-ray (Fig. 2a), was diagnosed as stage IIIA (cT1bN2M0) adenocarcinoma (Fig. 2a-d, Fig. 3). Serum carcinoembryonic antigen (CEA) was $553.2 \mathrm{ng} / \mathrm{ml}$. The primary lesion was in the 
Table 3 Comparison of characteristics among stage III and stage IV long-term survivors according to OS groups

\begin{tabular}{|c|c|c|c|c|c|c|c|c|}
\hline \multirow{2}{*}{$\begin{array}{l}\text { Groups } \\
\text { Variables }\end{array}$} & \multicolumn{4}{|l|}{ Stage III } & \multicolumn{4}{|l|}{ Stage IV } \\
\hline & $3 \leq \mathrm{OS}<5$ & $5 \leq$ OS (tumor + ) & $5 \leq \mathrm{OS}$ (tumor - ): $C R$ & $P$ value & $3 \leq \mathrm{OS}<5$ & $5 \leq$ OS (tumor + ) & $5 \leq \mathrm{OS}$ (tumor -): CR & $P$ value \\
\hline No. (\% of the all stage III or IV patients) & $13(7.9)$ & $12(7.3)$ & $12(7.3)$ & & $29(10.4)$ & $17(6.1)$ & $5(1.8)$ & \\
\hline Median OS & 1405 & $2238^{* *}$ & $2876^{* *}$ & $<0.01$ & 1368 & $2503^{* *}$ & $2643^{* *}$ & $<0.01$ \\
\hline (Range) - days & $(1097-1770)$ & $(1836-3315)$ & $(2271-4250)$ & & $(1109-1791)$ & $(1933-3862)$ & $(2160-4525)$ & \\
\hline Age (Median; Range) - yr. & $69.0 ; 50-78$ & $65.5 ; 54-79$ & $63.5 ; 41-79$ & 0.47 & $66 ; 37-89$ & $67 ; 41-76$ & $56 ; 36-69$ & 0.21 \\
\hline \multicolumn{9}{|l|}{ Sex-no. } \\
\hline Male & 10 & 8 & 11 & 0.33 & 14 & 12 & 4 & 0.20 \\
\hline Female & 3 & 4 & 1 & & 15 & 5 & 1 & \\
\hline \multicolumn{9}{|l|}{ Smoking status } \\
\hline Current & 4 & 4 & 8 & 0.18 & 9 & 6 & 4 & 0.15 \\
\hline Previous & 4 & 6 & 3 & & 6 & 6 & 1 & \\
\hline Never & 5 & 2 & 1 & & 14 & 5 & 0 & \\
\hline BMl & $21.9 \pm 2.97$ & $23.4 \pm 4.1$ & $21.2 \pm 1.85$ & 0.24 & $23.0 \pm 3.7$ & $21.7 \pm 2.5$ & $19.4 \pm 2.7$ & 0.10 \\
\hline \multicolumn{9}{|l|}{ Complication } \\
\hline +; no. (\%) & $11(85 \%)$ & $7(58 \%)$ & $6(50 \%)$ & 0.16 & 12 & 7 & 3 & 0.73 \\
\hline -; no. (\%) & $2(15 \%)$ & $5(42 \%)$ & $6(50 \%)$ & & 17 & 10 & 2 & \\
\hline Type of complication \# - no. & & & & 0.74 & & & & 0.62 \\
\hline COPD & 3 & 4 & 1 & & 3 & 0 & 1 & \\
\hline Pulmonary fibrosis & 2 & 1 & 0 & & 0 & 0 & 0 & \\
\hline Diabetes mellitus & 2 & 3 & 2 & & 5 & 1 & 2 & \\
\hline Heart and aortic diseases & 0 & 2 & 1 & & 4 & 1 & 1 & \\
\hline Previous cancer treatment & 3 & 1 & 1 & & 0 & 1 & 0 & \\
\hline Occupation $^{\$}$ & & & & 0.56 & & & & 0.60 \\
\hline $\begin{array}{l}\text { Manager, Professional and } \\
\text { Technician }\end{array}$ & 2 & 1 & 4 & & 8 & 7 & 2 & \\
\hline $\begin{array}{l}\text { Skilled agricultural, and } \\
\text { crafts and related trades }\end{array}$ & 5 & 4 & 4 & & 8 & 6 & 2 & \\
\hline $\begin{array}{l}\text { Others including no regular } \\
\text { occupation }\end{array}$ & 6 & 7 & 4 & & 13 & 4 & 1 & \\
\hline $\begin{array}{l}\text { Lymphocyte counts in blood } \\
\text { (no. / } \mu \text {; mean } \pm \text { SD) }\end{array}$ & $1,785 \pm 538$ & $2,249 \pm 803$ & $2,182 \pm 634$ & 0.29 & $1,735 \pm 503$ & $1,988 \pm 521$ & $2,413 \pm 710^{*}$ & $<0.05$ \\
\hline \multicolumn{9}{|c|}{ Histological characteristics of tumor - no. (\%) } \\
\hline Adenocarcinoma & 8 & 8 & 4 & 0.37 & 23 & 14 & 4 & 0.16 \\
\hline Large cell carcinoma & 0 & 0 & 0 & & 0 & 0 & 1 & \\
\hline Squamous cell carcinoma & 4 & 1 & 4 & & 2 & 1 & 0 & \\
\hline Not otherwise specified & 1 & 3 & 2 & & 2 & 0 & 0 & \\
\hline Other cell types & 0 & 0 & 2 & & 2 & 2 & 0 & \\
\hline EGFR mutation status & & & & 0.03 & & & & 0.28 \\
\hline Positive/Negative/Unknown & $3 / 2 / 8$ & $1 / 6 / 5$ & $0 / 1 / 11$ & & $7 / 6 / 16$ & $6 / 4 / 7$ & $0 / 3 / 2$ & \\
\hline \multicolumn{9}{|l|}{ ECOG performance status } \\
\hline 1 & 5 & 7 & 5 & 0.57 & 15 & 7 & 0 & 0.10 \\
\hline 0 & 8 & 5 & 7 & & 14 & 10 & 5 & \\
\hline $\begin{array}{l}\text { Primary tumor diameter } \\
(\mathrm{mm} \text {; mean } \pm \mathrm{SD})\end{array}$ & $38.7 \pm 22.9$ & $40.0 \pm 15.4$ & $30.0 \pm 18.6$ & 0.34 & $39.6 \pm 13.6$ & $29.6 \pm 14.4$ & $17.5 \pm 13.2^{* *}$ & $<0.01$ \\
\hline \multicolumn{9}{|l|}{ N factor - no. } \\
\hline N3 & 6 & 0 & 4 & 0.052 & 13 & 2 & 0 & $<0.05$ \\
\hline N2 & 6 & 11 & 5 & & 8 & 10 & 1 & \\
\hline N1 & 0 & 0 & 2 & & 3 & 0 & 1 & \\
\hline No & 1 & 1 & 1 & & 5 & 5 & 3 & \\
\hline
\end{tabular}

M factor - no. 
Table 3 Comparison of characteristics among stage III and stage IV long-term survivors according to OS groups (Continued)

\begin{tabular}{|c|c|c|c|c|c|c|c|c|}
\hline \multirow{2}{*}{$\begin{array}{l}\text { Groups } \\
\text { Variables }\end{array}$} & \multicolumn{4}{|l|}{ Stage III } & \multicolumn{4}{|l|}{ Stage IV } \\
\hline & $3 \leq$ OS $<5$ & $5 \leq$ OS (tumor + ) & $5 \leq$ OS (tumor -): CR & $P$ value & $3 \leq$ OS $<5$ & $5 \leq$ OS $($ tumor + ) & $5 \leq$ OS (tumor -): CR & $P$ value \\
\hline M1c & & & & & 6 & 3 & 0 & 0.28 \\
\hline M1b & & & & & 5 & 6 & 3 & \\
\hline M1a & & & & & 18 & 8 & 2 & \\
\hline $\begin{array}{l}\text { Total metastatic number at initial } \\
\text { diagnosis (no.; mean } \pm S D \text { ) }\end{array}$ & - & - & - & & $6.6 \pm 4.1$ & $5.2 \pm 3.8$ & $0.6 \pm 0.6^{* *}$ & $<0.05$ \\
\hline
\end{tabular}

BMI: body mass index, COPD: chronic obstructive pulmonary disease, EGFR: epidermal growth factor receptor, ECOG: Eastern Cooperative Oncology Group, ${ }^{*}: P<$ 0.05 and ${ }^{* *}: P<0.01$ compared with the $3 \leq$ OS $<5$ group. + denotes existence of any complication before treatment. -denotes existence of no complication before treatment. \#; Some patients had several complications. \$; The International Standard Classification of Occupations (ISCO)-08 was used for this occupational classification. "Not otherwise specified" was based on a pathological determination, with the features being as follows. First, the tumor was pathologically diagnosed as NSCLC. Second, the NSCLC could not be classified into subgroups, due to the lack of positive findings on cytology, hematoxylin-eosin staining and/ or immunohistochemical staining

All significant $P$ values are expressed in boldface, and not significant $P$ values are expressed in plainface

right middle lobe (Fig. 2b). Swelling of a right hilar and mediastinal lymph node was noted (Fig. 2c and Fig. 2d). This patient received a chemotherapeutic regimen with carboplatin + paclitaxel + bevacizumab. The primary lesion showed scar formation (Fig. 2e). However, PET/CT showed viable cells in a right hilar lymph node. Threedimensional conformal radiation therapy was planned for the right hilar and mediastinal lymph nodes (Fig. 2f). The total radiation dose was $60 \mathrm{~Gy}$. At 380 days after the initial treatment, fluorodeoxyglucose (FDG) accumulations at the primary lesion and a newly-involved mediastinal lymph node (\#3) were observed by PET/CT scan (Fig. 2g). Three-dimensional conformal radiation therapy for these lesions (total, 62.5Gy for each) was administered to control these lesions (Fig. 2h). This patient achieved CR (Fig. 2i), has maintained this CR over 5 years since initial treatment without previous one-year treatment.

Two representative CR patients with stage IV NSCLC, who received oligometastatic treatments with radiation and surgery, are shown in Fig. 4a-g and Fig. 4h-o. The first patient was treated with a chemotherapeutic regimen followed by EGFR-TKI, and the oligometastatic lesions were controlled with radiation and surgery (Fig. $4 \mathrm{a}-\mathrm{g}$ ). A male in his 50 s consulted our institution for dyspnea, and was hospitalized due to bilateral malignant pleural effusion, malignant pericardial effusion and cardiac tamponade (Fig. 4a and Fig. 4b). He was diagnosed as Stage IVA (cT1aN2M1a) adenocarcinoma (Fig. 5). Biopsy of an enlarged right-sided lower pretracheal lymph node (\#3) confirmed N2. After pericardial drainage, a chemotherapeutic regimen with cisplatin + gemcitabine was administered. After 4 courses of cisplatin + gemcitabine treatment, the pleural and pericardial effusions disappeared (Fig. 4c). Gefitinib was started. He complained of left femoral pain. Metastases were demonstrated by bone scintigraphy in the left femoral bone and left hip joint on day 548 (Fig. 4d). After the radiation therapy (total 45Gy: $3 \mathrm{~Gy} /$ fraction $\mathrm{x} 15$ fractions) to the left femoral area, joint replacement surgery was performed. The primary lesion gradually enlarged thereafter (Fig. 4e), and the mass in the right upper lobe of the lung was surgically removed (Fig. 4f). Pathological examination revealed this tumor to be an adenocarcinoma (Fig. 6) showing a mixture of the acinar subtype (Fig. 6a) and the solid type (Fig. 6b). The EGFR mutations were, however, negative. There were no mutations of EGFR exon 18 G719X, exon 21 L858R, exon 21 L861Q, exon 19 deletion, and exon $20 \mathrm{~T} 790 \mathrm{M}$. The patient was also negative for the Alk mutation based on the immunohistochemistry and fluorescence in situ hybridization (FISH) methods. Numerous inflammatory cell infiltration was observed around the tumor (Fig. 6a), and many lymphoid follicles were also detected in the resected lung tumor (Fig. 6b), demonstrating strong immune responses against the tumor. The CR has been maintained (Fig. $4 \mathrm{f}$ and Fig. 4g) over 5 years since initial treatment without previous one-year therapy.

Another stage IV CR patient with brain metastases is shown in Fig. 4h-o. He was treated with multiple chemotherapeutic regimens and primary surgical resection, and the brain metastases were controlled with SRT and brain surgeries. This male, in his 30s, consulted due to loss of consciousness. He was diagnosed as stage IVA (cT2aN0M1b) large cell carcinoma (Fig. 4h-i, Fig. 7) with a solitary brain metastasis (Fig. 4j). Cyber-knife therapy for the brain tumor was done. We planned to start chemotherapy, however, he developed pneumothorax. The operation on the primary lesion was decided before the initiation of chemotherapy. After 4 courses of a first-line chemotherapy regimen with cisplatin + docetaxel, three new brain metastases were observed in the left cerebellum, the right occipital lobe, and the left parietal lobe by head magnetic resonance imaging (MRI). Cyber-knife treatments to these three new brain metastases were done. He complained of headache. A new lesion in the left occipital lobe was observed (Fig. 4k), and the tumors in the left cerebellum and the right occipital 
Table 4 Univariate and multivariate analyses of the hazard ratios (HRs) among Stage III and stage IV long-term survivors

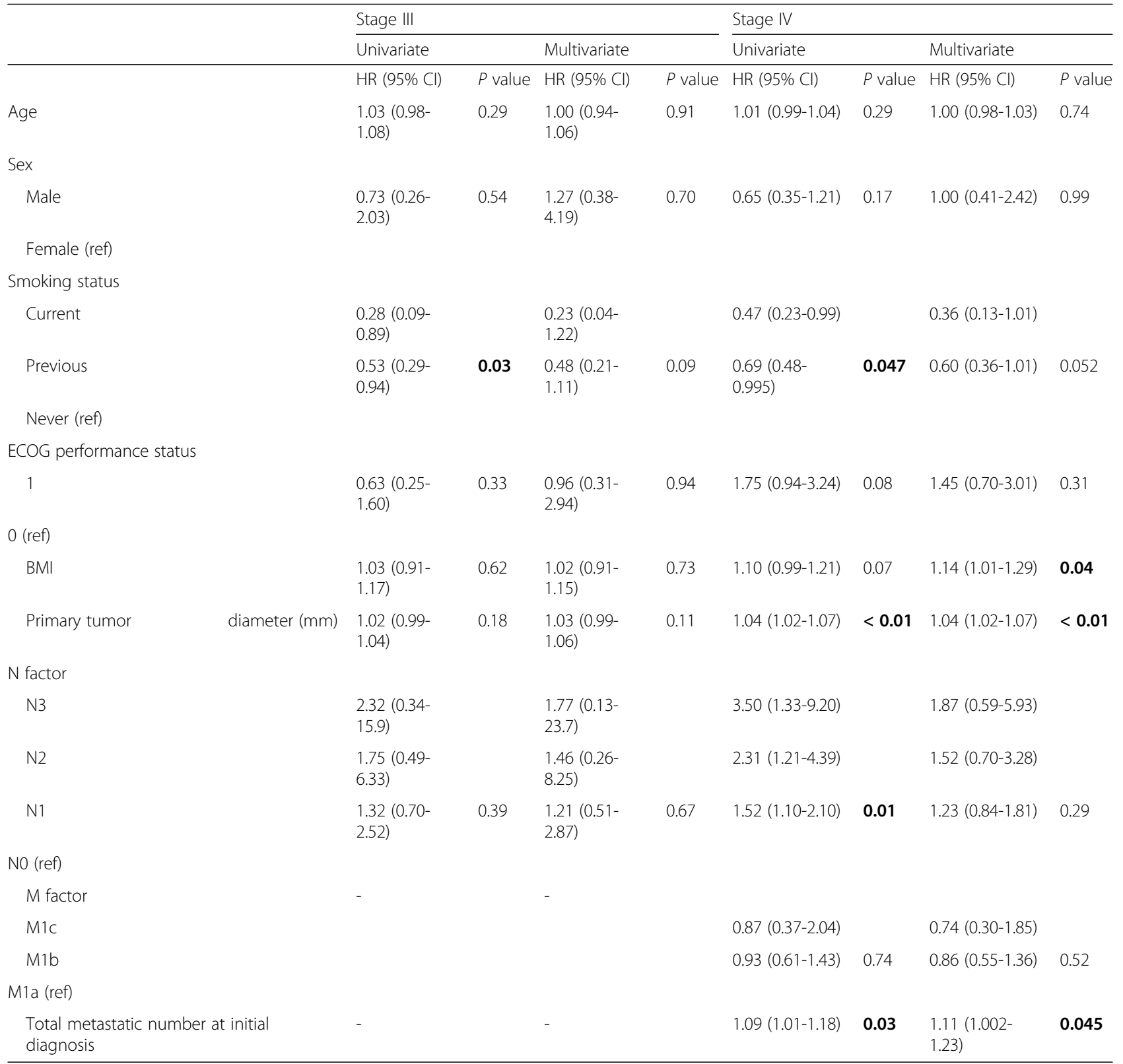

HR Hazard ration, ref reference.

All significant $P$ values are expressed in boldface, and not significant $P$ values are expressed in plainface

lobe (Fig. 4l) were getting large. Brain surgery was undertaken. Resected brain tumor in the right occipital lobe is shown in Fig. 8. Numerous inflammatory cell infiltration was observed around (Fig. 8a and b) and within (Fig. 8a and c) the metastatic brain carcinoma, showing marked immune response. Finally, the brain tumors and the lung tumor disappeared (Fig. $4 \mathrm{~m}-\mathrm{o})$. He has maintained CR for more than 5 years without previous one-year treatment.

Four tumors and one cranial dura mater specimen from two stage IV CR patients were histopathologically examined. Three tumors and one cranial dura mater specimen were obtained from the brain metastases of the patient presented in Fig. 4h-o, and also one pulmonary lung tumor from the patient shown in Fig. 4a-g. Strong inflammatory responses, which were confirmed by abundant inflammatory cell infiltrations, were observed in all of these lesions.

\section{Discussion}

This study, conducted in Japan, is the first to explore the features in CR cases of advanced NSCLC, including both stage III and stage IV. Among stage III patients, all CR patients received chemoradiation therapy, and no brain 
Table 5 Treatment differences among the groups of stage III and stage IV long-term survivors

\begin{tabular}{|c|c|c|c|c|c|c|c|c|}
\hline \multirow{2}{*}{$\begin{array}{l}\text { Variables } \\
\text { Groups }\end{array}$} & \multicolumn{4}{|l|}{ Stage III } & \multicolumn{4}{|l|}{ Stage IV } \\
\hline & $3 \leq \mathrm{OS}<5$ & $\begin{array}{l}5 \leq \text { OS } \\
\text { (tumor }+ \text { ) }\end{array}$ & $\begin{array}{l}5 \leq \mathrm{OS} \\
\text { (tumor -): } \mathrm{CR}\end{array}$ & $P$ value & $\begin{array}{l}3 \leq \\
\text { OS }<5\end{array}$ & $\begin{array}{l}5 \leq \text { OS } \\
\text { (tumor }+ \text { ) }\end{array}$ & $\begin{array}{l}5 \leq \mathrm{OS} \\
\text { (tumor-): } \mathrm{CR}\end{array}$ & $P$ value \\
\hline \multicolumn{9}{|l|}{ Chemotherapy } \\
\hline Treatment line No. (mean \pm SD) & $3.7 \pm 2.0$ & $3.7 \pm 2.8$ & $1.7 \pm 1.0^{*}$ & $<0.05$ & $5.9 \pm 2.5$ & $5.5 \pm 3.4$ & $2.0 \pm 1.4^{*}$ & $<0.05$ \\
\hline $\begin{array}{l}\text { Total cycle No. (include EGFR-TKI\#) } \\
(\text { mean } \pm \text { SD) }\end{array}$ & $16.3 \pm 10.2$ & $20.3 \pm 19.6$ & $10.2 \pm 11.7$ & 0.20 & $23.8 \pm 13.6$ & $25.1 \pm 18.4$ & $5.4 \pm 3.5^{* \#}$ & $<0.05$ \\
\hline \multicolumn{9}{|l|}{ EGFR-TKI usage } \\
\hline +; no. (\%) & $4(31 \%)$ & $3(25 \%)$ & $0(0 \%)$ & 0.12 & $20(69 \%)$ & $11(65 \%)$ & $1(20 \%)$ & 0.11 \\
\hline -; no. (\%) & $9(69 \%)$ & $9(75 \%)$ & $12(100 \%)$ & & 9 (31\%) & $6(35 \%)$ & $4(80 \%)$ & \\
\hline EGFR-TKI line No. & $\begin{array}{l}0.5 \pm 0.8 \min : 1 \\
\max : 2\end{array}$ & $\begin{array}{l}0.5 \pm 1.0 \\
\min : 1, \max : 3\end{array}$ & 0 & 0.13 & $\begin{array}{l}1.5 \pm 1.3 \\
\min : 1 \\
\max : 4\end{array}$ & $\begin{array}{l}1.1 \pm 1.1 \\
\min : 1 \\
\max : 3\end{array}$ & $\begin{array}{l}0.4 \pm 0.9 \\
\text { min: } 2, \max : \\
2\end{array}$ & 0.15 \\
\hline
\end{tabular}

Radiation

$$
\begin{aligned}
& \text { Primary } \\
& \text { +; no. (\%) } \\
& \text {-; no. (\%) }
\end{aligned}
$$$$
2(15 \%)
$$

Metastatic lesions other than brain

$$
+ \text {; no. (\%) }
$$$$
\text { ; no. (\%) }
$$$$
1(8 \%)
$$$$
12(92 \%)
$$

Both primary and metastatic lesions other than brain

$$
\begin{aligned}
& \text { +; no. (\%) } \\
& \text {-; no. (\%) }
\end{aligned}
$$

$12(92 \%)$

Surgery

$$
\begin{aligned}
& \text { Primary } \\
& + \text {; no. (\%) }
\end{aligned}
$$$$
1(8 \%)
$$$$
\text { -; no. (\%) }
$$$$
12(92 \%)
$$$$
3(25 \%)
$$$$
0(0 \%)
$$$$
9(75 \%)
$$$$
12(100 \%)
$$$$
12(100 \%)
$$$$
0(0 \%)
$$

0.09

$5(17 \%)$

$$
4(24 \%)
$$$$
2(40 \%)
$$$$
24(83 \%)
$$$$
13(76 \%)
$$$$
3(60 \%)
$$$$
3(25 \%) \quad 3(25 \%)
$$$$
0.43
$$$$
9(75 \%)
$$$$
9(75 \%)
$$

0.43

$11(38 \%)$

$5(29 \%)$

2 (40\%)

$18(62 \%)$

$12(71 \%)$

$3(60 \%)$

$3(25 \%) \quad 3(25 \%)$

0.43

$2(7 \%)$

$1(6 \%)$

$0(0 \%)$

$9(75 \%)$

$9(75 \%)$

27 (93\%)

$16(94 \%)$

$5(100 \%)$

Metastatic lesions other than brain

$$
\begin{array}{ll}
\text { +; no. (\%) } & 0(0 \%) \\
\text {-; no. (\%) } & 13(100 \%)
\end{array}
$$

$0(0 \%)$

$0(0 \%)$

$12(100 \%)$

$12(100 \%)$

0.13

$2(7 \%)$

$1(6 \%)$

$2(40 \%)$

0.06

Both primary and metastatic lesions other than brain

$$
\begin{array}{ll}
\text { +; no. (\%) } & 0(0 \%) \\
\text {-; no. (\%) } & 13(100 \%)
\end{array}
$$

$\begin{array}{ll}0(0 \%) & 0(0 \%) \\ 12(100 \%) & 12(100 \%)\end{array}$

1.00

$27(93 \%)$

$16(94 \%)$

$3(60 \%)$

1.00

$0(0 \%)$

$0(0 \%)$

$2(40 \%)$

$29(100 \%) \quad 17(100 \%) \quad 3(60 \%)$

Treatment of brain metastases

SRT

$$
\text { +; no. (\%) }
$$

; no. (\%)

$1(8 \%)$
$12(92 \%)$

$12(92 \%)$

$3(25 \%)$

$9(75 \%)$

$0(0 \%)$

$12(100 \%)$

0.13

$8(28 \%)$

$5(29 \%)$

$1(20 \%)$

0.92

Surgery

$$
\text { +; no. (\%) }
$$

$0(0 \%)$

$0(0 \%)$

$0(0 \%)$

$12(100 \%)$

$12(100 \%)$

1.00

$21(72 \%)$

$12(71 \%)$

$4(80 \%)$

$13(100 \%)$

WBI

$$
\text { +; no. (\%) }
$$

$1(8 \%)$

$1(8 \%)$

$0(0 \%)$

0.60

$1(3 \%)$

$1(6 \%)$

$1(20 \%)$

0.35

-; no. (\%)

12 (92\%)

11 (92\%)

$12(100 \%)$
$28(97 \%) \quad 16(94 \%) \quad 4(80 \%)$

$0.60 \quad 7(24 \%) \quad 3(18 \%) \quad 0(0 \%)$

0.44

\#: One continuous EGFR-TKI usage is considered as 1 cycle, ${ }^{*}:<0.05$ compared with the $3 \leq$ OS $<5$ group, ${ }^{\#:}<0.05$ compared with the $5 \leq$ OS with tumor (tumor +) group, + denotes done of the treatment. -denotes not-done of the treatment. Metastatic lesions include at initial diagnosis and during treatment course. All significant $P$ values are expressed in boldface, and not significant $P$ values are expressed in plainface 


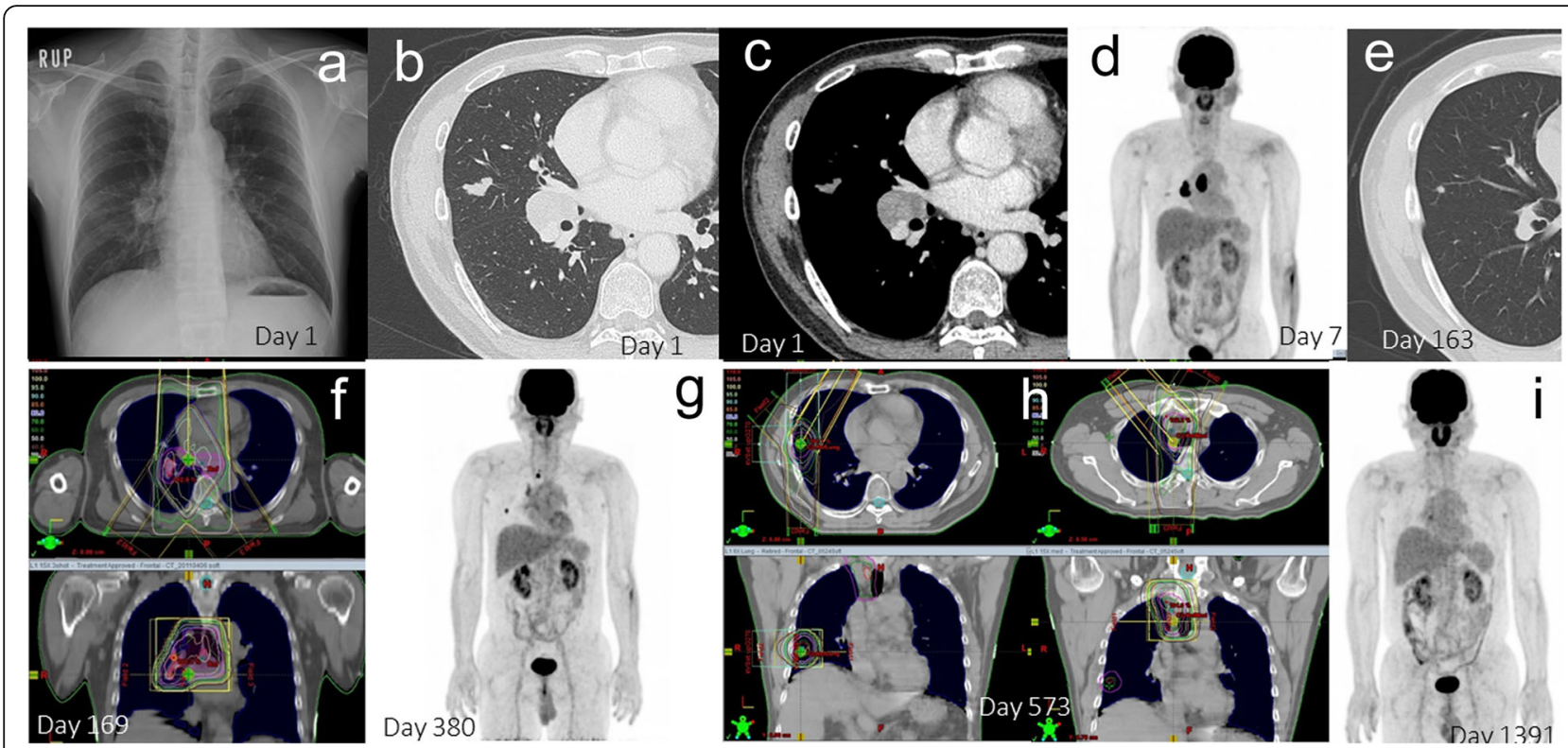

Fig. 2 A representative complete remission (CR) patient with oligometastases in stage III. A CR patient with stage III (a-i), in whom successful control of primary and oligometastatic lesions was obtained, is shown. A male in his 50s consulted our hospital due to an abnormal shadow recognized on a chest X-ray (a). The computed tomography (CT) revealed the primary lesion to be in the right middle lobe (b)), as well as swelling of a right hilar (c) and a mediastinal lymph node. Positron emission tomography (PET) / CT (d) and head magnetic resonance imaging (MRI) demonstrated the patient to have stage IIIA (CT1bN2M0) adenocarcinoma. The primary lesion showed scar formation after chemotherapy (e). However, PET/CT showed viable cells in the right hilar lymph node. Three-dimensional conformal radiation therapy was planned for the right hilar and mediastinal lymph nodes (f). On the day 380 since initial treatment, PET/CT revealed recurrence of the primary lesion and a new mediastinal lymph node metastasis $(\mathbf{g})$. Three-dimensional conformal radiation therapy was administered for these lesions (h). The PET/CT (i) and the head MRI demonstrated CR
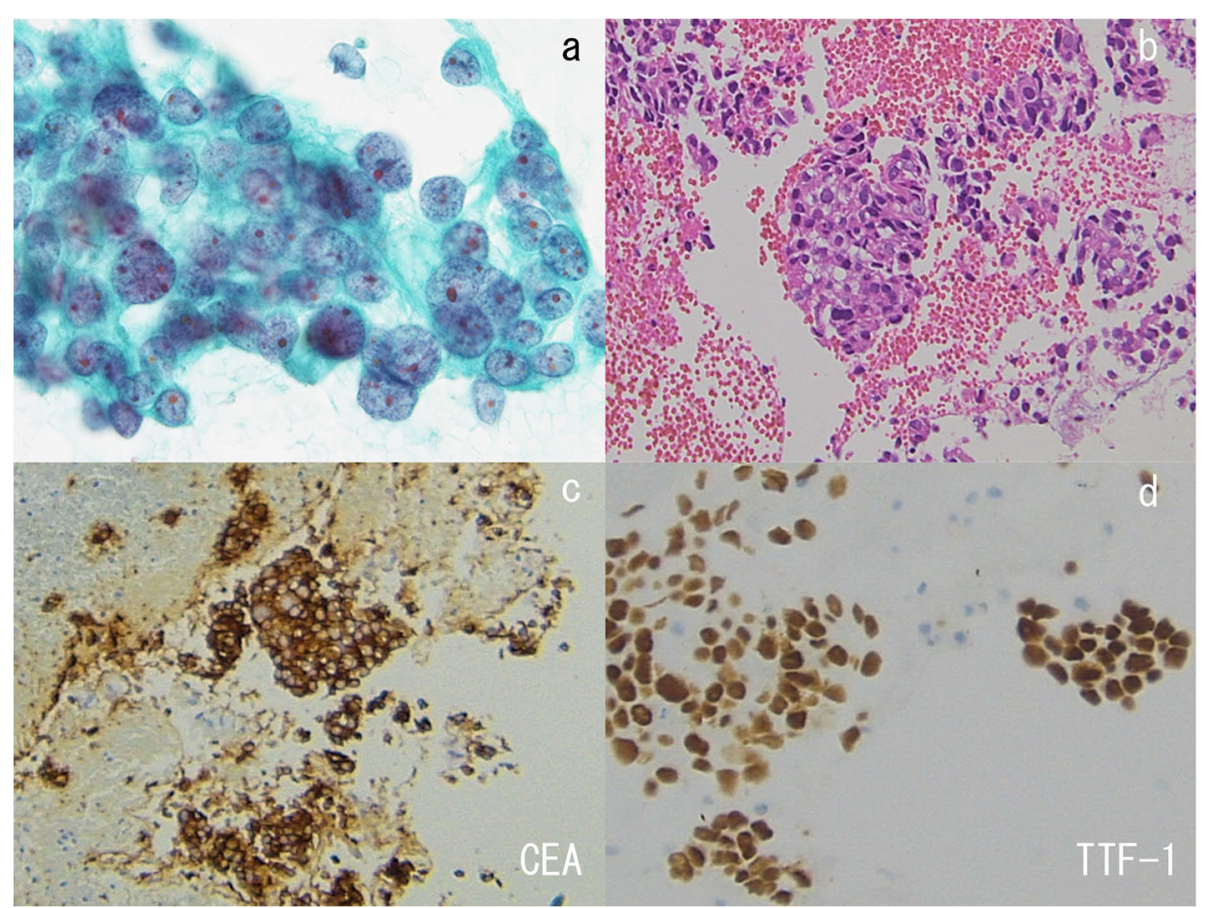

Fig. 3 Pathological findings in the stage III patient with complete remission (CR), shown in Fig. 2. Cytology by bronchoscopy was class $V$ according to the Papanicolaou staining (a). Histological examinations confirmed the diagnosis of adenocarcinoma, based on hematoxylin and eosin staining (b) and immunohistochemical staining for CEA (c) and TTF-1 (d). The carcinoma cells were positive for CEA (c) and TTF-1 (d) 


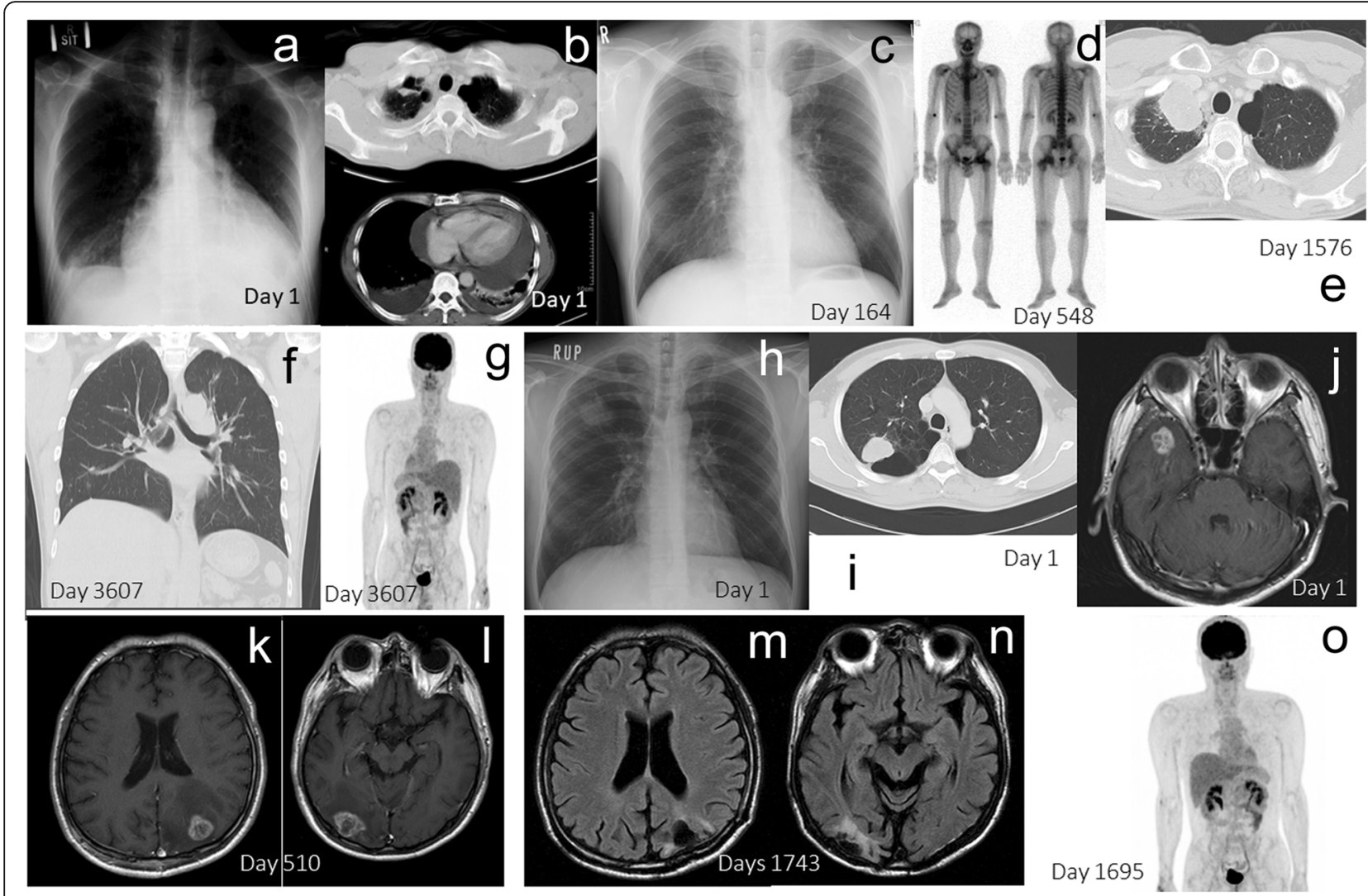

Fig. 4 Two representative complete remission (CR) patients with oligometastases in stage IV. The first CR patient in stage IV is shown in a-g. A male in his 50s presented with dyspnea, and bilateral malignant pleural and pericardial effusions were observed on the chest X-ray (a) and the CT (b). He was diagnosed as stage IVA (CT1aN2M1a) adenocarcinoma. After pericardial drainage followed by chemotherapy, the pleural and pericardial effusions disappeared (c). He complained of left femoral pain, and bone scintigraphy revealed bone metastases in the left femoral bone and left hip joint (d). After radiation therapy, he underwent joint replacement surgery. The primary lesion, located in the right upper lobe, showed gradual enlargement (e) and was surgically removed (f). The CR has since been maintained, based on head MRI and PET/CT (g). The second patient with brain metastases achieving CR is shown in h-o. A male in his 30s consulted our hospital due to loss of consciousness. A tumor was detected in the right upper lobe $(\mathbf{h}, \mathbf{i})$. There was no lymph node swelling, while a solitary brain metastasis was observed in the right temporal lobe (j). He was diagnosed as stage IVA (cT2aNOM1b) large cell carcinoma. Cyber-knife therapy for this lesion and surgery for the primary lesion were performed. After 4 courses of a first-line chemotherapy, three new brain metastases were detected in the left cerebellum, the right occipital lobe, and the left parietal lobe by head MRI. Cyber-knife treatments for these lesions were done. He subsequently complained of headache. Brain metastases in the left occipital lobe $(\mathbf{k})$, the left cerebellum, and the right occipital lobe (I) were demonstrated by head MRI. Brain surgeries were performed for these lesions. The brain tumors and the lung tumor ultimately disappeared, as shown by the head MRI ( $\mathbf{m}, \mathbf{n})$ and the PET/CT (o)

metastases occurred during the treatments without prophylactic WBI (Table 5). Distant metastases during the course of treatment, which are considered as oligometastases or oligorecurrence, were radically controlled by radiotherapies, not surgeries (Table 5 ). On the other hand, among stage IV patients, there were also CR patients with different characteristics from those of stage III patients (Table 3, Table 4, Table 5). The stage IV CR patients had smaller primary tumors and fewer metastases (Table 3, Table 4). The mean diameter was $17.5 \pm$ $13.2 \mathrm{~mm}$, and the mean metastatic number was $0.6 \pm$ 0.6 , indicating that these patients were stage IV with one distant metastasis or malignant pleural or pericardial effusion at the initial diagnosis, and there were no N3 patients. Even though smaller primary tumors and fewer metastases, treatments with surgery or radiation combined with systemic chemotherapies were necessary to control the primary and metastatic lesions, suggesting the difficulty of curing stage IV NSCLC patients.

The clinical characteristics of the $\mathrm{CR}$ patients were quite different between stage III and stage IV groups, showing that lung tumors have different biological identities between the two stages. Hence, we must possibly change the strategies for achieving complete cure according to whether NSCLC is stage III or stage IV. The features of the stage III CR patients in this study suggest that the active radical control of all oligometastases with radiation might be effective for inducing $\mathrm{CR}$ after 


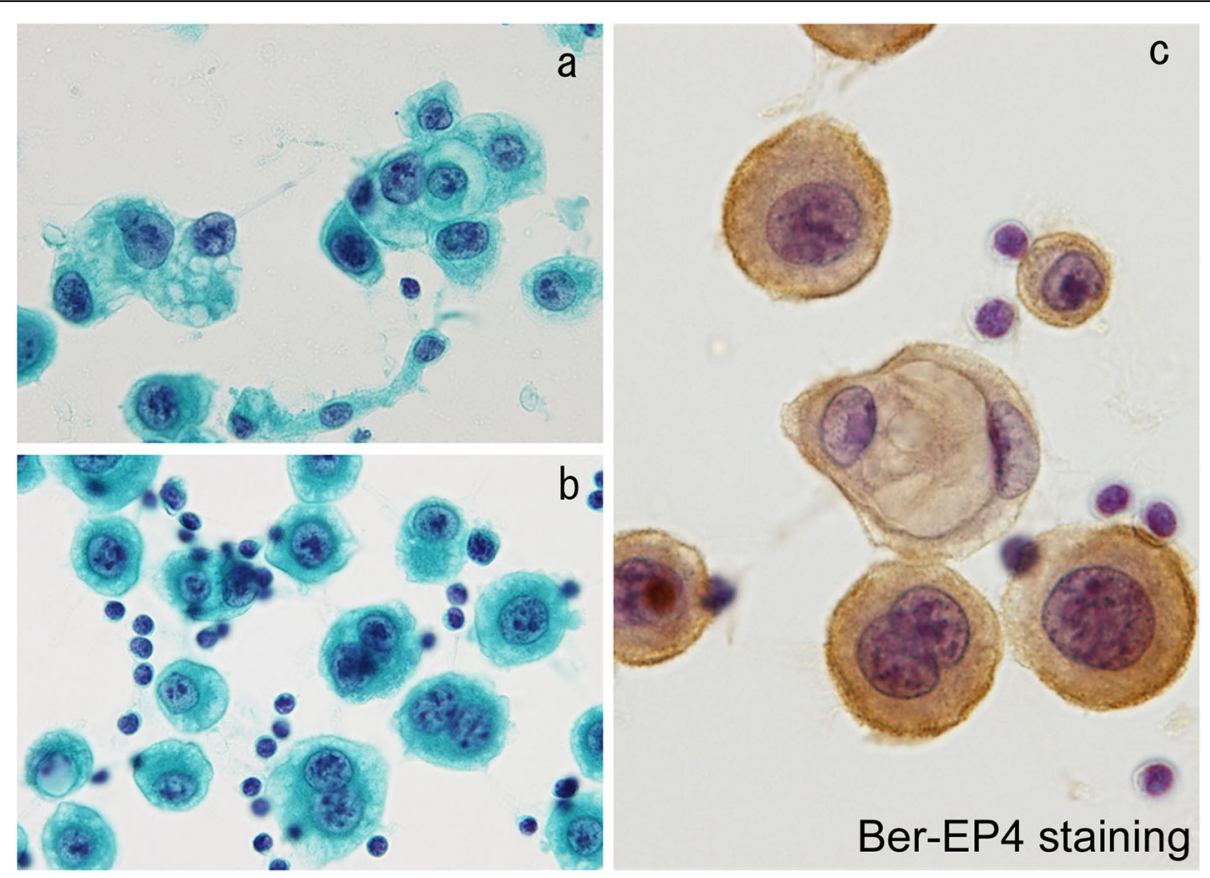

Fig. 5 Cytological findings in a stage IV patient with complete remission (CR), shown in Fig. 4a-g. Carcinoma cells were confirmed by

Papanicolaou staining of pericardial effusion $(\mathbf{a}, \mathbf{b})$. This carcinoma was a very aggressive type, based on the presence of numerous mitotic cells (b). Carcinoma cells stained positive for Ber-EP4 (c), indicating these cells to be adenocarcinoma, not mesothelioma

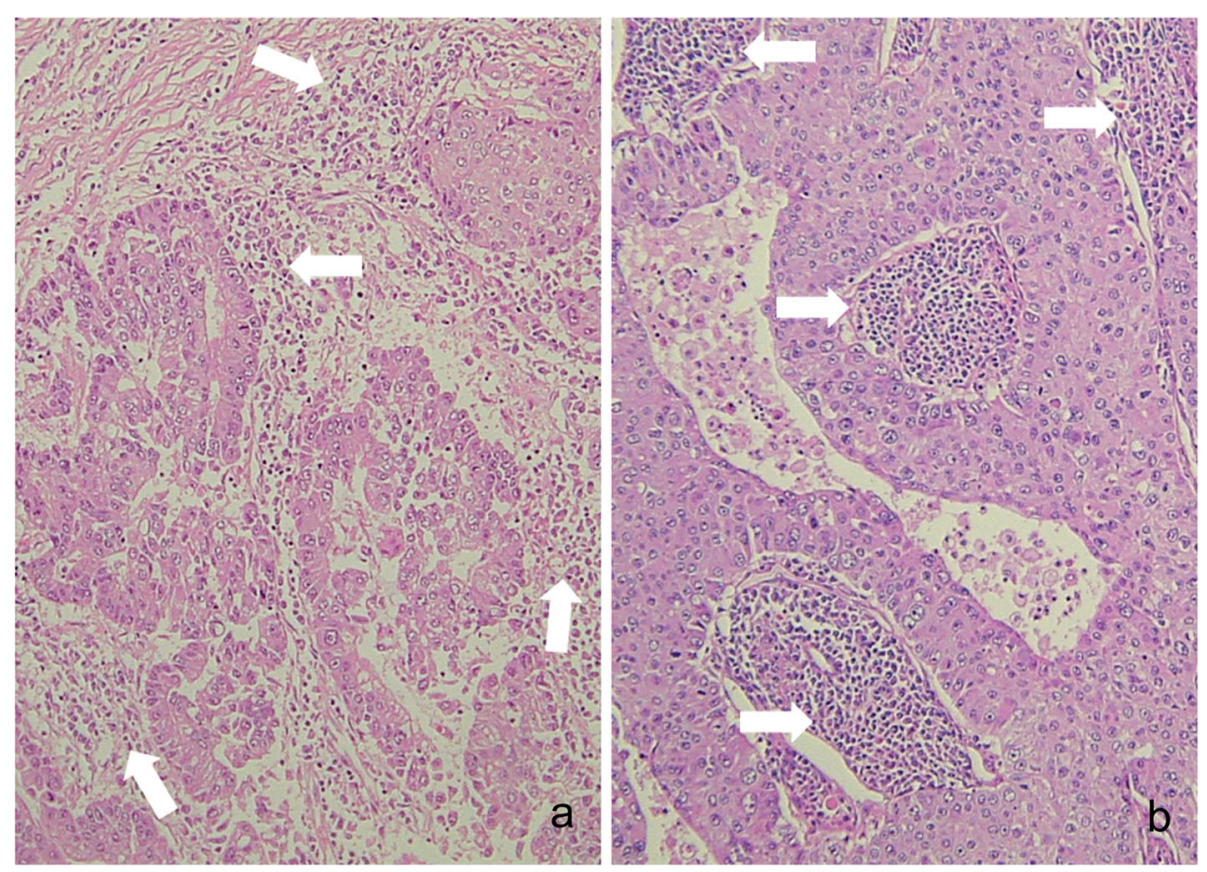

Fig. 6 Pathological findings of the lung tumor resected from the right upper lobe, shown in Fig. 4e. Hematoxylin and eosin staining of the resected tumor is shown. Pathological examination revealed this tumor to be an adenocarcinoma showing a mixture of the acinar type (a) and the solid type (b). Numerous inflammatory cells around (a) and inside (b) the tumor are indicated by the white arrows. A lot of lymphoid follicles are visible inside the tumor $(\mathbf{b})$. These inflammatory cells demonstrate marked immune response 


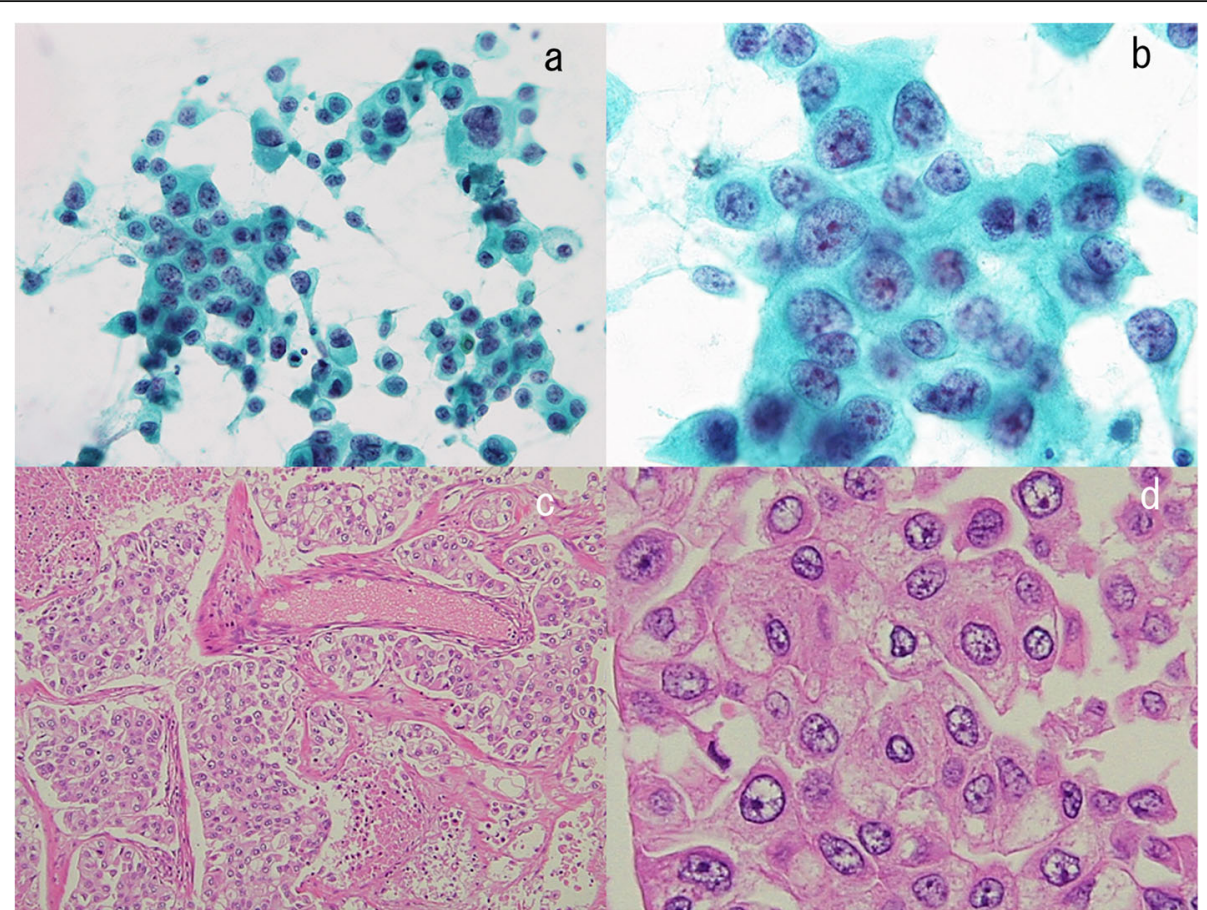

Fig. 7 Pathological findings in a stage IV patient with complete remission (CR), shown in Fig. 4h and i. Bronchoscopy was performed. Cytological examination revealed non-small cell type carcinoma, according to Papanicolaou staining (low power field; a, high power field; b). The surgically resected primary lung tumor (Fig. $4 \mathrm{~h}$ and i) was stained with hematoxylin and eosin (low power field; c, high power field; d). Large cell carcinoma was confirmed by pathological examination

chemoradiation, if brain metastases do not occur. Treatments with chemoradiation followed by durvalumab combined with the radical control of oligometastases are expected to increase cure rates in stage III patients, because a low incidence of new brain metastases with durvalumab was reported in the PACIFIC study [22], a hypothesis that requires confirmation in future clinical trials. Smoking is associated with tumor mutation burden and EGFR mutation status. Increased smoking, especially, induces high mutation burden in NSCLC, which might be attributable to decreased HRs in longterm survivors receiving continuous treatment in both
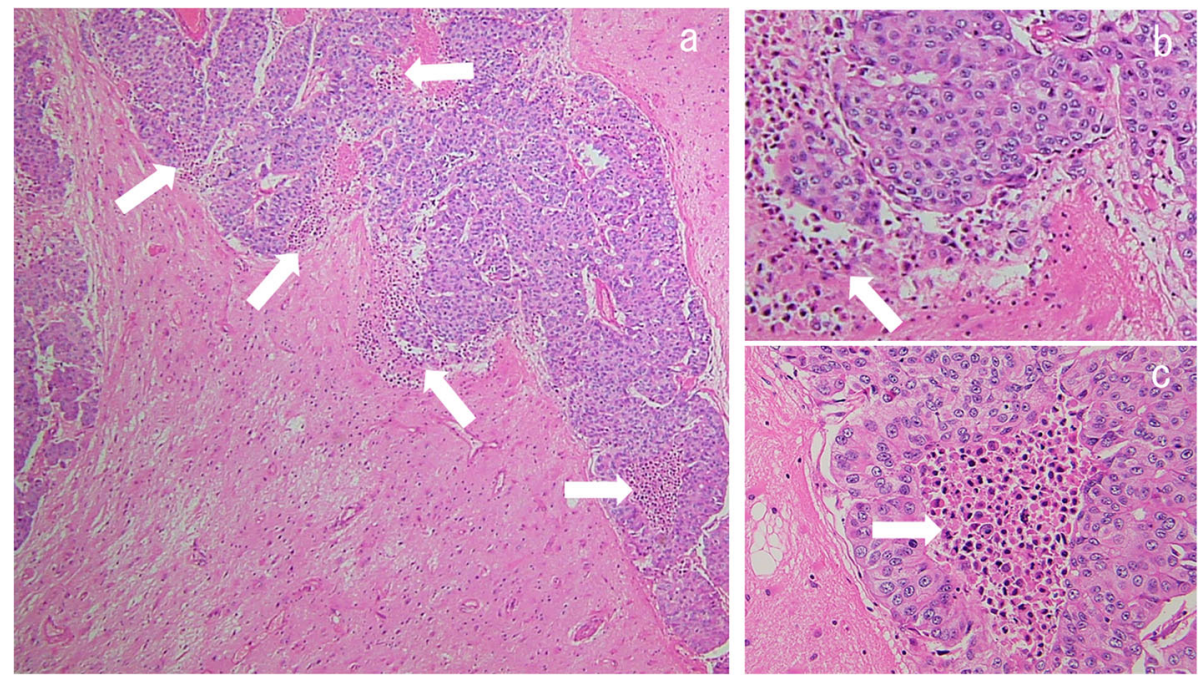

Fig. 8 Pathological findings of the resected brain tumor in the right occipital lobe in Fig. 4n. This slide shows hematoxylin and eosin staining of the lesion resected from the right occipital lobe (low power field; $\mathbf{a}$, high power field; $\mathbf{b}$ and $\mathbf{c}$ ). Metastatic large cell carcinoma was confirmed. There are inflammatory cells around (b) and inside (c) the carcinoma, indicating strong immune response 
stage III and stage IV, as demonstrated by univariate analysis (Table 4). There may be multiple confounding factors, due to which the HRs for smoking might disappear on multivariate analysis (Table 4).

Owing to the development of ICI with platinum doublet chemotherapy as a first-line treatment, a higher response rate and more extended OS were reported in phase 3 trials for both nonsquamous [48, 49] and squamous metastatic NSCLC [50]. The Keynote 189 clinical trial, which targeted metastatic nonsquamous NSCLC, reported that the estimated proportion of patients who were alive at 12 months was $69.2 \%$ in the pembrolizumab-pemetrexed-platinum group [48], and the IMpower 150 clinical trial also targeted metastatic nonsquamous NSCLC, and the median OS was reported as 19.2 months in the atezolizumab-bevacizumabpaclitaxel-platinum group [49]. The Keynote 407 clinical trial, which targeted metastatic squamous NSCLC, reported that the median OS was 15.9 months in the pembrolizumab-paclitaxel-platinum group [50]. Compared to those of previously reported phase 3 clinical trials, these recent results are surprisingly effective for the treatment of stage IV NSCLC. Moreover, in locally advanced unresectable stage III NSCLC, chemoradiation with ICI induced a higher response rate and longer median time to death or distant metastases, which were $28.4 \%$ and 23.2 months, respectively, in the durvalumab group in the PACIFIC study [22]. Taken together, in the treatment of both stage III and stage IV NSCLC, longterm survivors are obviously increased by adding ICI to the conventional standard treatments. However, cure strategies have not yet been developed. Therefore, we aimed to obtain clues for complete cure in this study. We considered a cure as sustained tumor disappearance over the 5-year period since initial chemotherapy or EGFR-TKI initiation, with no treatment for previous one year, which was defined as CR in this study.

In the resected tumors in the stage IV CR patients, abundant inflammatory cell infiltration was observed. The blood lymphocytes before treatment were also increased in the stage IV CR patients (Table 3). These findings, taken together with small tumors and few metastases, raise the following two possibilities in cured patients. First, host immune systems prevent tumor growth and the occurrence of metastases. Second, the growth speed of the tumor is low, and the ability of metastases is also low. In other words, if systemic treatments with ICI and/or chemotherapies control primary and metastatic sites for a long time, considered as a dormant state, active radical therapies for the remaining lesions might be expected to increase the cure rates of stage IV patients. Endo et al. [41] reported a similar conclusion, in a prospective study of 34 patients, showing that clinical T1-2 N0-1 lung cancer with a single-organ metastatic lesion was a good candidate for surgical resection, and a 5-year survival rate of approximately $40 \%$ can be expected. The prognostic importance of tumor-infiltrating lymphocytes and their potential predictive significance were recently reported in solid tumors including NSCLC [51]. Researches focusing on tumor-infiltrating lymphocytes are anticipated to yield further insights into their roles and functions in a tumor microenvironment.

By using the Kaplan-Meier method, the estimated OS in our study at the 3-year time point was 19\% for stage IV NSCLC patients (Fig. 1). The results of this study, obtained from chemotherapy without ICI, are comparable to the reported OS with ICI monotherapy. In the pooled analysis of the CheckMate 017 and CheckMate 057 phase III clinical trials, which targeted stage IIIB/IV squamous cell carcinoma and stage IIIB/IV nonsquamous cell carcinoma, respectively, the estimated OS at the 3-year time point was 17\% [52]. Continuous treatments with chemotherapies without ICI are suggested to have similar effects as ICI monotherapies, although the similarity was not statistically confirmed.

There are several limitations of this study. This study was a single institutional retrospective study, and future prospective multi-institutional clinical studies are necessary based on the results of this study. The statistical power to compare the groups might be low owing to the small number of patients, because CR patients are not common, particularly in stage IV. Lymphocytes might play a major role as immune cells, because neutrophils or myeloid derived suppressor cells are also abundant in NSCLC tissue and do not have beneficial effects on survival. Strong immune responses are shown in the tumor tissues derived from the stage IV CR patients, while we could not precisely distinguish individually these tumorinfiltrating cells. Nevertheless, we believe that the results of this analysis provide effective clues for developing further clinical trials to cure advanced NSCLC.

\section{Conclusion}

In summary, this retrospective study demonstrated that $\mathrm{CR}$ are possible in certain patients by controlling primary lesions and oligometastases through surgery and/ or radiation combined with chemotherapies, even in advanced NSCLC. All stage III CR patients received chemoradiation therapy with oligometastatic control by radiation therapies, and no brain metastases occurred during the treatment course. On the other hand, stage IV CR patients had smaller primary tumors and fewer metastases among the long-term survivors, there were no N3 patients, and marked inflammatory cell infiltration was observed in the surgically resected lung and brain tumors, suggesting the importance of host immune response against lung cancer. 


\section{Abbreviations}

ALK-TKI: anaplastic lymphoma kinase-tyrosine kinase inhibitors; ASCO: The American Society of Clinical Oncology; BMI: body mass index; BRAF: v-raf murine sarcoma viral oncogene homolog B1; CEA: carcinoembryonic antigen; Cl: confidence intervals; CR: complete remission; CTLA-4: cytotoxic Tlymphocyte antigen 4; ECOG: Eastern Cooperative Oncology Group; EGFRTKI: epidermal growth factor receptor-tyrosine kinase inhibitors; FDG: fluorodeoxyglucose; FISH: fluorescence in situ hybridization; HRs: hazard ratios; IASLC: The International Association for the Study of Lung Cancer; ICl: immune checkpoint inhibitors; MRI: magnetic resonance imaging; NCCN: The National Comprehensive Cancer Network; NSCLC: non-small cell lung cancer; OS: overall survival time; PD-1: programmed cell death 1; PET/ CT: positron emission tomography / computed tomography; PS: performance status; RET: rearranged during transfection; RFA: radiofrequency ablation; ROS-1: c-ros oncogene 1; SRT: stereotactic radiotherapy; UMIN: university hospital medical information network; WBI: whole brain irradiation

\section{Acknowledgments}

The authors are profoundly grateful to Dr. Bierta Barfod, MD, MPH for proofreading the manuscript. The authors are grateful to Ms. Miki Yamashita for her assistance in this study. The authors are also grateful to Dr. Yukihiro Horio, Dr. Naoki Okada, Dr. Keito Enokida, Dr. Shigeaki Hattori, Dr. Shohei Obayashi, Dr. Tomoe Takeuchi, Dr. Fuminari Takahashi, and Dr. Kazuki Harada, all of whom belong to the Respiratory Division, Department of Internal Medicine, Tokai University School of Medicine, for the care of patients and the invaluable assistance of this study.

\section{Authors' contributions}

T.Aoki, S.T., N.H., J.T., M.S., H. Takiguchi, H. Tomomatsu, K.T., T.T., K.N., T.O. and T.U. treated and followed patients. T. Akiba and E. K treated patients with radiation therapy. J.N. and M.M. performed brain surgeries. M.K., R.M. and M.I. performed thoracic surgeries. H.I., H.K., and N.N. performed the pathological analyses. N.N., E.K., M.M., M.I. and K.A. supervised the study and contributed to interpreting the results. T. Aoki designed the study. All coauthors read and approved the final manuscript.

\section{Funding}

This research was supported by the Japan Society for the Promotion of Science (JSPS) KAKENHI (Grant Number JP16K09555 [to Takuya Aoki]).

\section{Availability of data and materials}

The dataset used and/or analyzed during the current study are available from the corresponding author on reasonable request.

\section{Ethics approval and consent to participate}

The study was performed in accordance with the Declaration of Helsinki. This study protocol was approved by the institutional review board for clinical research, Tokai University (14R-054). The study was announced by the poster and the internet to the public. There is no individual written informed consent due to the retrospective nature of the study. In the presentation of the representative complete remission cases, written informed consent from the individuals for publication was obtained and the approval of the institutional review board was also obtained.

\section{Consent for publication}

Not applicable

\section{Competing interests}

The authors declare no conflicts of interest.

\section{Author details}

${ }^{1}$ Respiratory Division, Department of Internal Medicine, Tokai University School of Medicine, Isehara, Kanagawa 259-1193, Japan. ${ }^{2}$ Department of Radiation Oncology, Tokai University School of Medicine, Isehara, Kanagawa 259-1193, Japan. ${ }^{3}$ Department of Neurosurgery, Tokai University School of Medicine, Isehara, Kanagawa 259-1193, Japan. ${ }^{4}$ Department of Thoracic Surgery, Tokai University School of Medicine, Isehara, Kanagawa 259-1193, Japan. ${ }^{5}$ Department of Pathology, Tokai University School of Medicine, Isehara, Kanagawa 259-1193, Japan.
Received: 1 September 2019 Accepted: 7 November 2019

Published online: 21 November 2019

\section{References}

1. Chemotherapy in non-small cell lung cancer: a meta-analysis using updated data on individual patients from 52 randomised clinical trials. Non-small Cell Lung Cancer Collaborative Group. BMJ. 1995;311:899-909.

2. Schiller JH, Harrington D, Belani CP, Langer C, Sandler A, Krook J, Zhu J, Johnson $\mathrm{DH}$. Comparison of four chemotherapy regimens for advanced non-small-cell lung cancer. N Engl J Med. 2002;346:92-8.

3. Ohe Y, Ohashi Y, Kubota K, Tamura T, Nakagawa K, Negoro S, Nishiwaki Y, Saijo N, Ariyoshi Y, Fukuoka M. Randomized phase III study of cisplatin plus irinotecan versus carboplatin plus paclitaxel, cisplatin plus gemcitabine, and cisplatin plus vinorelbine for advanced non-small-cell lung cancer: Four-Arm Cooperative Study in Japan. Ann Oncol. 2007;18:317-23.

4. Paez JG, Janne PA, Lee JC, Tracy S, Greulich H, Gabriel S, Herman P, Kaye FJ, Lindeman N, Boggon TJ, et al. EGFR mutations in lung cancer: correlation with clinical response to gefitinib therapy. Science. 2004;304:1497-500.

5. Lynch TJ, Bell DW, Sordella R, Gurubhagavatula S, Okimoto RA, Brannigan BW, Harris PL, Haserlat SM, Supko JG, Haluska FG, et al. Activating mutations in the epidermal growth factor receptor underlying responsiveness of nonsmall-cell lung cancer to gefitinib. N Engl J Med. 2004;350:2129-39.

6. Brahmer JR, Drake CG, Wollner I, Powderly JD, Picus J, Sharfman WH, Stankevich E, Pons A, Salay TM, McMiller TL, et al. Phase I study of singleagent anti-programmed death-1 (MDX-1 106) in refractory solid tumors: safety, clinical activity, pharmacodynamics, and immunologic correlates. J Clin Oncol. 2010;28:3167-75.

7. Mok TS, Wu YL, Thongprasert S, Yang CH, Chu DT, Saijo N, Sunpaweravong P, Han B, Margono B, Ichinose Y, et al. Gefitinib or carboplatin-paclitaxel in pulmonary adenocarcinoma. N Engl J Med. 2009;361:947-57.

8. Maemondo M, Inoue A, Kobayashi K, Sugawara S, Oizumi S, Isobe H, Gemma A, Harada M, Yoshizawa H, Kinoshita I, et al. Gefitinib or chemotherapy for non-small-cell lung cancer with mutated EGFR. N Engl J Med. 2010;362:2380-8.

9. Mitsudomi T, Morita S, Yatabe Y, Negoro S, Okamoto I, Tsurutani J, Seto T, Satouchi M, Tada H, Hirashima T, et al. Gefitinib versus cisplatin plus docetaxel in patients with non-small-cell lung cancer harbouring mutations of the epidermal growth factor receptor (WJTOG3405): an open label, randomised phase 3 trial. Lancet Oncol. 2010;11:121-8.

10. Solomon BJ, Mok T, Kim DW, Wu YL, Nakagawa K, Mekhail T, Felip E, Cappuzzo F, Paolini J, Usari T, et al. First-line crizotinib versus chemotherapy in ALK-positive lung cancer. N Engl J Med. 2014;371:2167-77.

11. Hida T, Nokihara H, Kondo M, Kim YH, Azuma K, Seto T, Takiguchi Y, Nishio $\mathrm{M}$, Yoshioka $\mathrm{H}$, Imamura $\mathrm{F}$, et al. Alectinib versus crizotinib in patients with ALK-positive non-small-cell lung cancer (J-ALEX): an open-label, randomised phase 3 trial. Lancet. 2017;390:29-39.

12. Peters S, Camidge DR, Shaw AT, Gadgeel S, Ahn JS, Kim DW, Ou SI, Perol M, Dziadziuszko R, Rosell R, et al. Alectinib versus Crizotinib in Untreated ALKPositive Non-Small-Cell Lung Cancer. N Engl J Med. 2017;377:829-38.

13. Shaw AT, Ou SH, Bang YJ, Camidge DR, Solomon BJ, Salgia R, Riely GJ, Varella-Garcia M, Shapiro GI, Costa DB, et al. Crizotinib in ROS1-rearranged non-small-cell lung cancer. N Engl J Med. 2014;371:1963-71.

14. Planchard D, Smit EF, Groen HJM, Mazieres J, Besse B, Helland A, Giannone V, D'Amelio AM Jr, Zhang P, Mookerjee B, Johnson BE. Dabrafenib plus trametinib in patients with previously untreated BRAF(V600E)-mutant metastatic non-small-cell lung cancer: an open-label, phase 2 trial. Lancet Oncol. 2017;18:1307-16.

15. Drilon A, Rekhtman N, Arcila M, Wang L, Ni A, Albano M, Van Voorthuysen M, Somwar R, Smith RS, Montecalvo J, et al. Cabozantinib in patients with advanced RET-rearranged non-small-cell lung cancer: an open-label, singlecentre, phase 2, single-arm trial. Lancet Oncol. 2016;17:1653-60.

16. Yoh K, Seto T, Satouchi M, Nishio M, Yamamoto N, Murakami H, Nogami N, Matsumoto S, Kohno T, Tsuta K, et al. Vandetanib in patients with previously treated RET-rearranged advanced non-small-cell lung cancer (LURET): an open-label, multicentre phase 2 trial. Lancet Respir Med. 2017;5:42-50.

17. Borghaei H, Paz-Ares L, Horn L, Spigel DR, Steins M, Ready NE, Chow LQ, Vokes EE, Felip E, Holgado E, et al. Nivolumab versus Docetaxel in Advanced Nonsquamous Non-Small-Cell Lung Cancer. N Engl J Med. 2015;373:1627-39.

18. Brahmer J, Reckamp KL, Baas P, Crino L, Eberhardt WE, Poddubskaya E, Antonia S, Pluzanski A, Vokes EE, Holgado E, et al. Nivolumab versus 
Docetaxel in Advanced Squamous-Cell Non-Small-Cell Lung Cancer. N Engl J Med. 2015;373:123-35.

19. Herbst RS, Baas P, Kim DW, Felip E, Perez-Gracia JL, Han JY, Molina J, Kim JH, Arvis $\mathrm{CD}$, Ahn MJ, et al. Pembrolizumab versus docetaxel for previously treated, PD-L1-positive, advanced non-small-cell lung cancer (KEYNOTE-010): a randomised controlled trial. Lancet. 2016;387:1540-50.

20. Reck M, Rodriguez-Abreu D, Robinson AG, Hui R, Csoszi T, Fulop A, Gottfried M, Peled N, Tafreshi A, Cuffe S, et al. Pembrolizumab versus Chemotherapy for PD-L1-Positive Non-Small-Cell Lung Cancer. N Engl J Med. 2016;375: 1823-33.

21. Rittmeyer A, Barlesi F, Waterkamp D, Park K, Ciardiello F, von Pawel J, Gadgeel SM, Hida T, Kowalski DM, Dols MC, et al. Atezolizumab versus docetaxel in patients with previously treated non-small-cell lung cancer (OAK): a phase 3, open-label, multicentre randomised controlled trial. Lancet. 2017:389:255-65.

22. Antonia SJ, Villegas A, Daniel D, Vicente D, Murakami S, Hui R, Yokoi T, Chiappori A, Lee KH, de Wit M, et al. Durvalumab after Chemoradiotherapy in Stage III Non-Small-Cell Lung Cancer. N Engl J Med. 2017;377:1919-29.

23. Ishida Y, Agata Y, Shibahara K, Honjo T. Induced expression of PD-1, a novel member of the immunoglobulin gene superfamily, upon programmed cell death. Embo j. 1992;11:3887-95.

24. Brunet JF, Denizot F, Luciani MF, Roux-Dosseto M, Suzan M, Mattei MG, Golstein P. A new member of the immunoglobulin superfamily--CTLA-4. Nature. 1987;328:267-70.

25. Nishimura H, Nose M, Hiai H, Minato N, Honjo T. Development of lupus-like autoimmune diseases by disruption of the PD-1 gene encoding an ITIM motif-carrying immunoreceptor. Immunity. 1999;11:141-51.

26. Krummel MF, Allison JP. CD28 and CTLA-4 have opposing effects on the response of T cells to stimulation. J Exp Med. 1995;182:459-65.

27. Tivol EA, Borriello F, Schweitzer AN, Lynch WP, Bluestone JA, Sharpe AH. Loss of CTLA-4 leads to massive lymphoproliferation and fatal multiorgan tissue destruction, revealing a critical negative regulatory role of CTLA-4. Immunity. 1995;3:541-7.

28. Leach DR, Krummel MF, Allison JP. Enhancement of antitumor immunity by CTLA-4 blockade. Science. 1996;271:1734-6.

29. Hodi FS, O'Day SJ, McDermott DF, Weber RW, Sosman JA, Haanen JB, Gonzalez R, Robert C, Schadendorf D, Hassel JC, et al. Improved survival with ipilimumab in patients with metastatic melanoma. N Engl J Med. 2010; 363:711-23.

30. Topalian SL, Hodi FS, Brahmer JR, Gettinger SN, Smith DC, McDermott DF, Powderly JD, Carvajal RD, Sosman JA, Atkins MB, et al. Safety, activity, and immune correlates of anti-PD-1 antibody in cancer. $N$ Engl J Med. 2012;366:2443-54.

31. Langer CJ, Gadgeel SM, Borghaei H, Papadimitrakopoulou VA, Patnaik A, Powell SF, Gentzler RD, Martins RG, Stevenson JP, Jalal SI, et al. Carboplatin and pemetrexed with or without pembrolizumab for advanced, nonsquamous non-small-cell lung cancer: a randomised, phase 2 cohort of the open-label KEYNOTE-021 study. Lancet Oncol. 2016;17:1497-508.

32. Rizvi NA, Hellmann MD, Brahmer JR, Juergens RA, Borghaei H, Gettinger S, Chow LQ, Gerber DE, Laurie SA, Goldman JW, et al. Nivolumab in Combination With Platinum-Based Doublet Chemotherapy for First-Line Treatment of Advanced Non-Small-Cell Lung Cancer. J Clin Oncol. 2016; 34:2969-79.

33. Hellman S, Weichselbaum RR. Oligometastases. J Clin Oncol. 1995;13:8-10.

34. Tree AC, Khoo VS, Eeles RA, Ahmed M, Dearnaley DP, Hawkins MA, Huddart RA, Nutting CM, Ostler PJ, van As NJ. Stereotactic body radiotherapy for oligometastases. Lancet Oncol. 2013;14:e28-37.

35. Senan S, Rusthoven CG, Slotman BJ, Siva S. Progress in Radiotherapy for Regional and Oligometastatic Disease in 2017. J Thorac Oncol. 2018;13:488-96.

36. David EA, Clark JM, Cooke DT, Melnikow J, Kelly K, Canter RJ. The Role of Thoracic Surgery in the Therapeutic Management of Metastatic Non-Small Cell Lung Cancer. J Thorac Oncol. 2017;12:1636-45.

37. Kim C, Hoang CD, Kesarwala AH, Schrump DS, Guha U, Rajan A. Role of Local Ablative Therapy in Patients with Oligometastatic and Oligoprogressive NonSmall Cell Lung Cancer. J Thorac Oncol. 2017;12:179-93.

38. Modesto A, Giron J, Massabeau C, Sans N, Berjaud J, Mazieres J. Radiofrequency ablation for non-small-cell lung cancer in a single-lung patient: case report and review of the literature. Lung Cancer. 2013;80:341-3.

39. Collen C, Christian N, Schallier D, Meysman M, Duchateau M, Storme G, De Ridder M. Phase II study of stereotactic body radiotherapy to primary tumor and metastatic locations in oligometastatic nonsmall-cell lung cancer patients. Ann Oncol. 2014;25:1954-9.

40. Petty WJ, Urbanic JJ, Ahmed T, Hughes R, Levine B, Rusthoven K, Papagikos M, Ruiz JR, Lally BE, Chan M, et al. Long-Term Outcomes of a Phase 2 Trial of Chemotherapy With Consolidative Radiation Therapy for Oligometastatic Non-Small Cell Lung Cancer. Int J Radiat Oncol Biol Phys. 2018;102:527-35.

41. Endo C, Hasumi T, Matsumura Y, Sato N, Deguchi H, Oizumi H, Sagawa M, Tsushima T, Takahashi S, Shibuya J, et al. A prospective study of surgical procedures for patients with oligometastatic non-small cell lung cancer. Ann Thorac Surg. 2014;98:258-64.

42. Johnson KK, Rosen JE, Salazar MC, Boffa DJ. Outcomes of a Highly Selective Surgical Approach to Oligometastatic Lung Cancer. Ann Thorac Surg. 2016; 102:1166-71.

43. Gomez DR, Blumenschein GR Jr, Lee JJ, Hernandez M, Ye R, Camidge DR, Doebele RC, Skoulidis F, Gaspar LE, Gibbons DL, et al. Local consolidative therapy versus maintenance therapy or observation for patients with oligometastatic non-small-cell lung cancer without progression after firstline systemic therapy: a multicentre, randomised, controlled, phase 2 study. Lancet Oncol. 2016;17:1672-82.

44. De Ruysscher D, Wanders R, Hendriks LE, van Baardwijk A, Reymen B, Houben R, Bootsma G, Pitz C, van Eijsden L, Dingemans AC. ProgressionFree Survival and Overall Survival Beyond 5 Years of NSCLC Patients With Synchronous Oligometastases Treated in a Prospective Phase II Trial (NCT 01282450). J Thorac Oncol. 2018;13:1958-61.

45. lyengar P, Lau S, Donington JS, Suh RD. Local Therapy for Limited Metastatic Non-Small Cell Lung Cancer: What Are the Options and Is There a Benefit? Am Soc Clin Oncol Educ Book. 2016;35:e460-7.

46. Palma DA, Olson R, Harrow S, Gaede S, Louie AV, Haasbeek C, Mulroy L, Lock M, Rodrigues GB, Yaremko BP, et al. Stereotactic ablative radiotherapy versus standard of care palliative treatment in patients with oligometastatic cancers (SABR-COMET): a randomised, phase 2, open-label trial. Lancet. 2019; 393:2051-8.

47. Goldstraw P, Chansky K, Crowley J, Rami-Porta R, Asamura H, Eberhardt WE, Nicholson AG, Groome P, Mitchell A, Bolejack V. The IASLC Lung Cancer Staging Project: Proposals for Revision of the TNM Stage Groupings in the Forthcoming (Eighth) Edition of the TNM Classification for Lung Cancer. J Thorac Oncol. 2016;11:39-51.

48. Gandhi L, Rodriguez-Abreu D, Gadgeel S, Esteban E, Felip E, De Angelis F, Domine M, Clingan P, Hochmair MJ, Powell SF, et al. Pembrolizumab plus Chemotherapy in Metastatic Non-Small-Cell Lung Cancer. N Engl J Med. 2018;378:2078-92.

49. Socinski MA, Jotte RM, Cappuzzo F, Orlandi F, Stroyakovskiy D, Nogami N, Rodriguez-Abreu D, Moro-Sibilot D, Thomas CA, Barlesi F, et al. Atezolizumab for First-Line Treatment of Metastatic Nonsquamous NSCLC. N Engl J Med. 2018;378:2288-301

50. Paz-Ares L, Luft A, Vicente D, Tafreshi A, Gumus M, Mazieres J, Hermes B, Cay Senler F, Csoszi T, Fulop A, et al. Pembrolizumab plus Chemotherapy for Squamous Non-Small-Cell Lung Cancer. N Engl J Med. 2018;379:2040-51.

51. Hendry S, Salgado R, Gevaert T, Russell PA, John T, Thapa B, Christie M, van de Vijver K, Estrada MV, Gonzalez-Ericsson PI, et al. Assessing TumorInfiltrating Lymphocytes in Solid Tumors: A Practical Review for Pathologists and Proposal for a Standardized Method from the International ImmunoOncology Biomarkers Working Group: Part 2: TILs in Melanoma, Gastrointestinal Tract Carcinomas, Non-Small Cell Lung Carcinoma and Mesothelioma, Endometrial and Ovarian Carcinomas, Squamous Cell Carcinoma of the Head and Neck, Genitourinary Carcinomas, and Primary Brain Tumors. Adv Anat Pathol. 2017;24:311-35.

52. Vokes EE, Ready N, Felip E, Horn L, Burgio MA, Antonia SJ, Aren Frontera O, Gettinger S, Holgado E, Spigel D, et al. Nivolumab versus docetaxel in previously treated advanced non-small-cell lung cancer (CheckMate 017 and CheckMate 057): 3-year update and outcomes in patients with liver metastases. Ann Oncol. 2018;29:959-65.

\section{Publisher's Note}

Springer Nature remains neutral with regard to jurisdictional claims in published maps and institutional affiliations. 